\title{
Article \\ Inhibition on $\alpha$-Glucosidase Activity and Non-Enzymatic Glycation by an Anti-Oxidative Proteoglycan from Ganoderma lucidum
}

\author{
Ying Zhang ${ }^{1}$, Yanna Pan ${ }^{1}$, Jiaqi Li ${ }^{1}$, Zeng Zhang ${ }^{2}$, Yanming He ${ }^{2}$, Hongjie Yang ${ }^{2, *}$ and Ping Zhou ${ }^{1, *(D)}$ \\ 1 State Key Laboratory of Molecular Engineering of Polymers, Department of Macromolecular Science, \\ Fudan University, Shanghai 200433, China; 19210440005@fudan.edu.cn (Y.Z.); \\ 18110440051@fudan.edu.cn (Y.P.); 20210440013@fudan.edu.cn (J.L.) \\ 2 Yueyang Hospital of Integrated Traditional Chinese and Western Medicine, Shanghai University of Traditional \\ Chinese Medicine, Shanghai 200437, China; zengzeng31@163.com (Z.Z.); heyanming176@163.com (Y.H.) \\ * Correspondence: yanghongiie1964@aliyun.com (H.Y.); pingzhou@fudan.edu.cn (P.Z.); \\ Tel./Fax: +86-21-3124-4038 (P.Z.)
}

check for updates

Citation: Zhang, Y.; Pan, Y.; Li, J.;

Zhang, Z.; He, Y.; Yang, H.; Zhou, P. Inhibition on $\alpha$-Glucosidase Activity and Non-Enzymatic Glycation by an Anti-Oxidative Proteoglycan from Ganoderma lucidum. Molecules 2022, 27, 1457. https://doi.org/ 10.3390/molecules 27051457

Academic Editors: Guglielmina Froldi and Helen Osborn

Received: 27 January 2022

Accepted: 19 February 2022

Published: 22 February 2022

Publisher's Note: MDPI stays neutral with regard to jurisdictional claims in published maps and institutional affiliations.

Copyright: (C) 2022 by the authors. Licensee MDPI, Basel, Switzerland. This article is an open access article distributed under the terms and conditions of the Creative Commons Attribution (CC BY) license (https:// creativecommons.org/licenses/by/ $4.0 /)$.

\begin{abstract}
The prevention of postprandial hyperglycemia and diabetic complications is crucial for diabetes management. Inhibition of $\alpha$-glucosidase to slow carbohydrate metabolism is a strategy to alleviate postprandial hyperglycemia. In addition, suppression of non-enzymatic glycation can diminish the advanced glycation end products and reduce the oxidative stress and inflammation, thereby preventing the diabetic complications. In this study, an anti-oxidative proteoglycan (named FYGL) extracted from Ganoderma lucidum was investigated in vitro for its inhibitory effect on $\alpha$ glucosidase and non-enzymatic glycation using molecular kinetics, intrinsic fluorescence assay, and bovine serum albumin glycation models. The molecular kinetics and fluorescence assay revealed that FYGL decreases $\alpha$-glucosidase activity by forming a FYGL- $\alpha$-glucosidase complex. To evaluate the anti-glycation effect, fructose-glycated and methylglyoxal-glycated BSA models were analyzed by spectroscopic and SDS-PAGE methods. Results showed that FYGL inhibited the glycation at every stage and suppressed glycoxidation, possibly due to its anti-oxidative capacity and FYGL-BSA complex formation. Furthermore, we demonstrated in vivo that FYGL could alleviate postprandial hyperglycemia in $d b / d b$ mice as well as AGE accumulation and vascular injury in diabetic rats. Overall, FYGL possesses anti-postprandial hyperglycemia and anti-glycation functions and would be potentially used in clinic for diabetes and related complication management.
\end{abstract}

Keywords: Ganoderma lucidum; postprandial hyperglycemia; $\alpha$-glucosidase; non-enzymatic glycation; advanced glycation end products (AGEs)

\section{Introduction}

Diabetes is a common metabolic disease characterized by hyperglycemia. Postprandial blood glucose (PBG) and fasting blood glucose (FBG) are two major indicators of hyperglycemia. High postprandial blood glucose accelerates the occurrence of microvascular and macrovascular complications as well as type II diabetes [1]. Strict control of PBG is very important for the prevention and management of diabetes mellitus [2]. After meals, postprandial blood glucose reaches its peak due to the digestion of carbohydrates such as starch and sucrose in food. Starch is decomposed into oligosaccharides or disaccharides by $\alpha$-amylase in the saliva and pancreatic juice and then further decomposed into absorbable glucose by $\alpha$-glucosidase at the brush edge of small intestinal epithelial cells, leading to the PBG peak reached. Inhibiting the $\alpha$-glucosidase activity can alleviate postprandial hyperglycemia [3]; therefore, finding efficient $\alpha$-glucosidase inhibitors (AGIs) has gained much attention [4]. In addition, continuous hyperglycemia in diabetic patients accelerates non-enzymatic glycation and increases the production of advanced glycation end products 
(AGEs) [5]. AGEs are formed in the extracellular matrix (ECM), such as elastin and lipids, resulting in the denaturation of its constitution and the stiffness of the matrix. Furthermore, AGEs interact with their receptor on vascular endothelial cell surfaces, leading to the activation of the pathway of AGE and its receptor (RAGE) and oxidative stress and inflammation [6], which accelerate diabetic complications, especially vascular complications [7]. Therefore, inhibiting AGE formation is particularly important to protect against diabetic vascular injury and other complications [8].

The drugs acarbose, miglitol, and voglibose have been clinically proven to control postprandial hyperglycemia by inhibiting $\alpha$-glucosidase activity [9]. However, these AGIs have gastrointestinal side effects to some extent, such as abdominal distention, intestinal distress, abdominal pain, and diarrhea [10]. Furthermore, aminoguanidine (AG), a synthetic AGE inhibitor, has been forbidden in clinic due to its adverse effects, such as anemia and gastrointestinal disturbances [11]. In recent years, natural products have been found to be safe and have been given more attention to alleviate postprandial hyperglycemia and non-enzymatic glycation $[12,13]$.

The mushroom Ganoderma lucidum has been used in traditional medicine for more than 2000 years in China to improve health, increase vitality, and extend life [14]. Ganoderma lucidum contains various bioactive compounds, such as polysaccharides, triterpenes, proteins, proteoglycans, sterols, fatty acids, and so on [15]. It has been proved to have anti-tumor, anti-diabetic, anti-inflammatory, and anti-oxidative functions [16-19]. In our previous study, we extracted a proteoglycan, named FYGL (Fudan-Yueyang-G. lucidum), from Ganoderma lucidum and found it to be a water-soluble, highly branched proteoglycan with a molecular weight of $2.6 \times 10^{5}$ Da [20]. FYGL contains polysaccharides and covalently bonded protein by -O- linkage through Ser and Thr residues. The polysaccharide dominantly contains arabinose, galactose, glucose, rhamnose, etc., and the protein contains most natural amino acids, as shown in Figure 1, characterized by chemical and multi-spectroscopic analysis [21,22]. Previous work demonstrated that FYGL exhibited anti-hyperglycemic effects through the inhibition of both the activity and expression of protein tyrosine phosphatase 1B (PTP1B) [20,23], an insulin-resistant protein. However, the effect of FYGL on $\alpha$-glucosidase and glycation is still unknown.

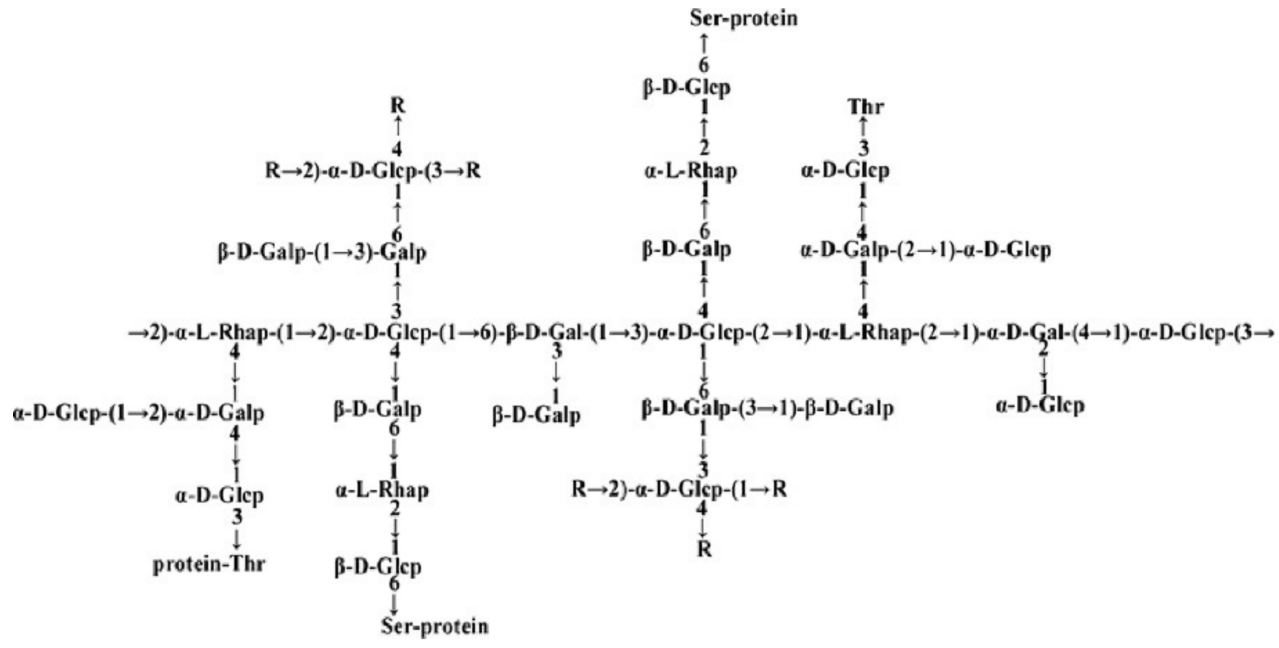

(A)

Figure 1. Cont. 


$\begin{array}{lccccc}\text { MEDEVAALVI } & \text { DNGSGMCKAG } & \text { FAGDDAPRAV } & \text { FPSIVGRPRH } & \text { QGVMVGMGQK } & \text { DSYVGDEAQS } \\ \text { KRGVLTLKYP } & \text { IEHGIVTNWD } & \text { DMEKIWHHTF } & \text { YNELRVAPEE } & \text { HPVLLTEAPL } & \text { NPKANREKMT } \\ \text { QIMFETFNAP } & \text { AFYVAIQAVL } & \text { SLYASGRTTG } & \text { IVLDSGDGVT } & \text { HTVPIYEGFS } & \text { LPHAILRIDL }_{180} \\ \text { AGRDLTEFLI } & \text { KNLMERGYPF } & \text { HTTAEREIVR } & \text { DIKEKLCYVA } & \text { LDFEQELQTA } & \text { AHSSALEKSY }_{240} \\ \text { ELPDGQVITI } & \text { GNERFRAPEA } & \text { LFQPAFLGLE } & \text { AAGIHETTYN } & \text { SIYKCDLDIR } & \text { RDLYGNIVLS }_{300} \\ \text { GGTTMFPGIA } & \text { DRMQKELTAL } \text { APSSMKVKIV } & \text { APPERKYSWW } & \text { IGGSILASLS }^{\text {TFQNLWCSKQ }} \\ \text { EYDESGPGIV } & \text { HRKCF }_{375} & & & & \end{array}$

(B)

Figure 1. (A) The dominant polysaccharide structure of FYGL (Fudan-Yueyang-G. lucidum) characterized by chemical and multi-spectroscopic analysis [21]. Ara: arabinose, Gal: galactose, Glc: glucose, Rha: rhamnose. Thr: threonine, Ser: serine. Protein moieties are covalently bonded with carbohydrate moieties by Ser and Thr residues in -O- linkage. (B) The dominant sequence of the protein moieties of FYGL characterized by mass spectroscopy [22].

In this study, inhibition of $\alpha$-glucosidase activity and non-enzymatic glycation by FYGL were evaluated both in vitro and in vivo. In vitro, the kinetic model of FYGL inhibiting $\alpha$ glucosidase activity and the interaction between FYGL and $\alpha$-glucosidase were investigated. Furthermore, the inhibitory effect of FYGL on non-enzymatic glycation was studied at three stages of the glycation process, identified by the formation of typical fructosamine, dicarbonyl compounds, and AGEs at the different stages, respectively, using the fructoseglycated model established in bovine serum albumin (BSA) [24]. Methylglyoxal (MGO) is one of the highly reactive dicarbonyl compounds generated at the middle stage of the glycation process [25] which was further used to establish a BSA glycated model, BSAMGO model, to evaluate the effect of FYGL on the end stage of the glycation process. Simultaneously, the glycoxidation and fibrillation of proteins occurring in the glycation process and FYGL's anti-glycation mechanism were investigated as well. In addition, to conform the results in vitro, the effect of FYGL in vivo on postprandial hyperglycemia was evaluated by oral sucrose tolerance test (OSTT) in $d b / d b$ mice and that on diabetic vascular injury by histopathology and AGE accumulation in aortic tissues of diabetic rats. The present research would attempt to provide scientific evidence for FYGL as a novel anti-diabetic and anti-glycation agent used in diabetes management and treatment.

\section{Results and Discussion}

\subsection{Anti-Postprandial Hyperglycemic Effect of FYGL In Vitro}

2.1.1. Inhibition Rate of $\alpha$-Glucosidase by FYGL

The inhibitory capacity of $F Y G L$ and acarbose on $\alpha$-glucosidase activity was studied using $p$-nitrophenyl- $\alpha$-D-glucopyranoside ( $p$ NPG) as substrate. Figure $2 \mathrm{~A}, \mathrm{~B}$ show the inhibition rate curves of FYGL and acarbose (positive control) at different concentrations. With the concentration of FYGL increased, the inhibition rate of $\alpha$-glucosidase activity was increased. These results indicated that FYGL inhibited $\alpha$-glucosidase activity in a dosedependent manner. When the concentration reached $750 \mu \mathrm{g} / \mathrm{mL}, \alpha$-glucosidase activity was almost completely inhibited. Logistic fitting analysis for curves showed that the $\mathrm{IC}_{50}$ values of FYGL and acarbose were $45.45 \mu \mathrm{g} / \mathrm{mL}$ and $1485.32 \mu \mathrm{g} / \mathrm{mL}$, respectively, implying that the inhibitory capacity of FYGL on $\alpha$-glucosidase was greater than that of acarbose. 


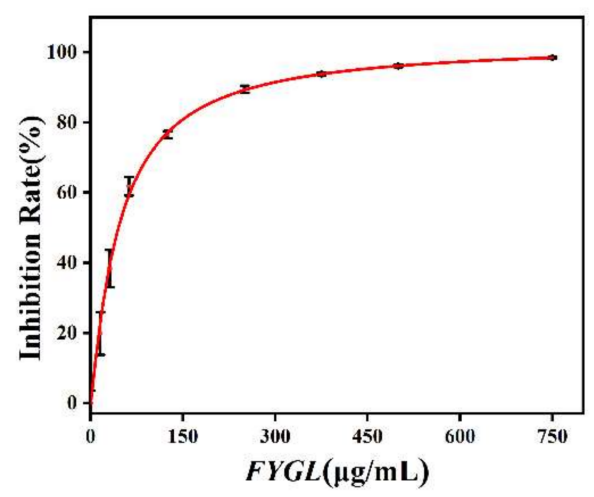

(A)

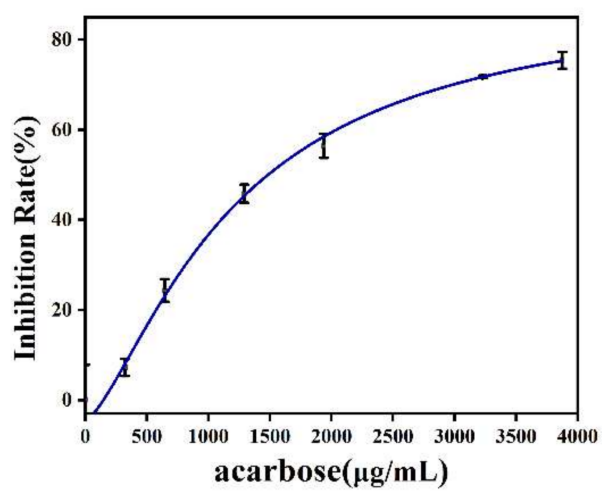

(B)

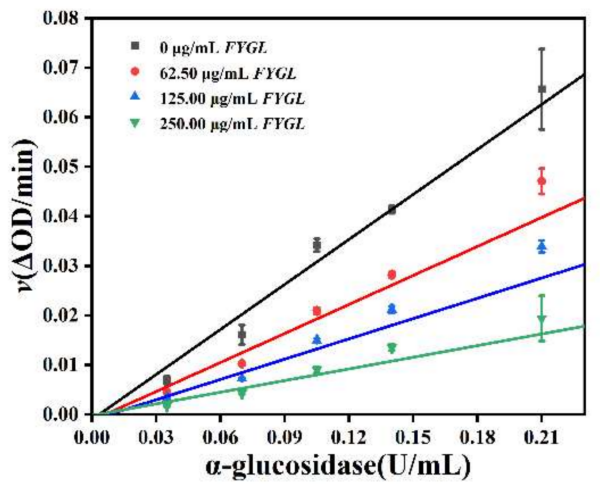

(C)

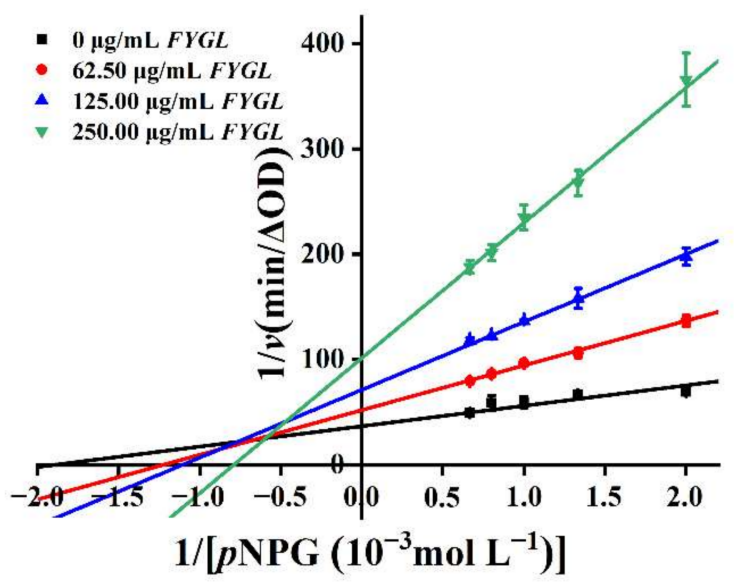

(D)

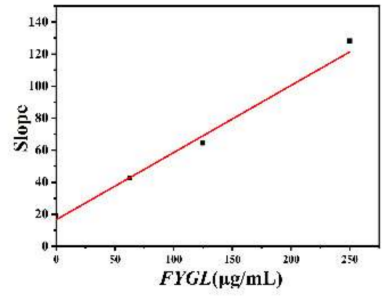

(E)

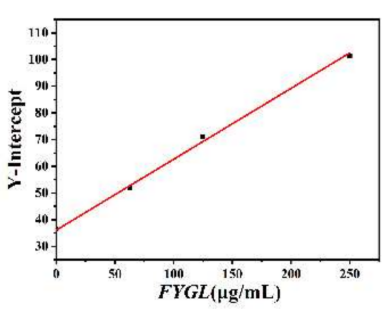

(F)

Figure 2. Inhibitory effect of FYGL (A) and acarbose (B) on $\alpha$-glucosidase. (C) Dependence of enzymatic rate $v$ vs. $\alpha$-glucosidase concentration at different FYGL concentrations. (D) LineweaverBurk curves of $1 / v$ vs. 1/[pNPG], effected by FYGL. Dependences of the slopes (E) and y-intercepts (F) in (D) vs. FYGL concentration. Each value represents the mean $\pm \mathrm{SD}(n=3)$. 


\subsubsection{Inhibitory Model of $F Y G L$ on $\alpha$-Glucosidase Activity}

To explore the inhibition model of FYGL on $\alpha$-glucosidase, the kinetics were investigated. As shown in Figure 2C, the enzymatic reaction rate $v$ increased as the enzyme concentration increased at different concentrations of FYGL, where the $v$ value was the change in absorbance at $405 \mathrm{~nm}$ per min over $30 \mathrm{~min}$. All of the fitted curves of the enzyme reaction rate at different FYGL concentrations passed through the origin, and the slopes of the lines decreased as the FYGL concentration increased, indicating that the inhibition of $\alpha$-glucosidase was reversible and the intermolecular interaction between FYGL and $\alpha$ glucosidase was non-covalent [26]. In addition, Lineweaver-Burk double reciprocal curves of the dependences of $1 / v$ vs. $1 /[\mathrm{pNPG}]$ at different $F Y G L$ concentrations were plotted as Figure 2D, in which all of the lines intersected at a point of $(-x,+y)$ in the orthogonal coordinates, where $\mathrm{x}, \mathrm{y}>0$, indicating that FYGL caused a mixed-model inhibition, which suggested that FYGL could competitively bind to free $\alpha$-glucosidase as well as noncompetitively to the enzyme-substrate complex. A similar inhibition effect was also found in sericin peptide [27], tannic acid [28], and some other natural products [29].

The mixed-model inhibition can be described by Lineweaver-Burk plots as Equation (1), and the slope and y-intercept plots can be described in Equations (2) and (3), respectively:

$$
\begin{gathered}
\frac{1}{v}=\frac{K_{m}}{v_{\max }}\left(1+\frac{[\mathrm{I}]}{K_{i}}\right) \frac{1}{[\mathrm{~S}]}+\frac{1}{v_{\max }}\left(1+\frac{[\mathrm{I}]}{K_{\mathrm{is}}}\right) \\
\text { Slope }=\frac{K_{m}}{v_{\max }}+\frac{K_{m}}{v_{\max }} \frac{1}{K_{i}}[\mathrm{I}] \\
\mathrm{Y}-\text { intercept }=\frac{1}{v_{\max }}+\frac{1}{v_{\max } K_{\mathrm{is}}}[\mathrm{I}]
\end{gathered}
$$

where [I] and [S] denote the concentration of inhibitor and substrate, respectively; $v$ is the enzyme reaction rate; and $K_{m}, K_{i}$, and $K_{i s}$ represent the Michaelis-Menten constant, the dissociation constant between free $\alpha$-glucosidase and inhibitor, and the dissociation constant between enzyme-substrate complex and inhibitor, respectively $[27,30]$. The kinetic parameters of $K_{i}$ and $K_{i s}$ can be calculated by Equations (2) and (3).

Figure 2E,F show the linear dependences of the slopes and y-intercepts in Figure 2D vs. different concentrations of FYGL, respectively, which suggested that there was one site or one type of site in $\alpha$-glucosidase interacting with FYGL [31]. Furthermore, the dissociation constant of $K_{i}$ and the dissociation constant of $K_{i s}$ were calculated to be $39.60 \mu \mathrm{g} / \mathrm{mL}$ and $135.88 \mu \mathrm{g} / \mathrm{mL}$, respectively, based on the slopes of Figure 2E,F, which suggested that FYGL was more likely to bind with free $\alpha$-glucosidase and competitive inhibition played a dominant role. A similar inhibition model was also found in kaempferol [32] and tannic acid [28].

\subsubsection{Fluorescence Quenching of $\alpha$-Glucosidase by FYGL}

Fluorescence quenching of a fluorophore is generally caused by the reaction of the excited state, transformation of energy, formation of ground state complex, collision of molecules, and so on, leading to the decrease in fluorescence quantum yield. $\alpha$-Glucosidase contains endogenous fluorophores, such as tryptophan, tyrosine, and phenylalanine residues, all of which are aromatic amino acids [33]. Herein, the fluorescence quenching of $\alpha$-glucosidase effected by FYGL was investigated.

Figure 3A shows the fluorescence spectra of $\alpha$-glucosidase effected by FYGL with excitation at $280 \mathrm{~nm}$. As the concentration of FYGL increased, the fluorescence intensity of $\alpha$-glucosidase gradually decreased. FYGL quenched the endogenous fluorescence of the enzyme in a concentration-dependent manner, indicating that FYGL interacted with $\alpha$-glucosidase. Figure 3B shows the fluorescence quenching rate of $\alpha$-glucosidase effected by FYGL at $326 \mathrm{~nm}$, and the half-quenching concentration of FYGL on $\alpha$-glucosidase fluorescence was calculated to be $21.46 \mu \mathrm{g} / \mathrm{mL}$, which was consistent with its half-inhibition concentration $\left(\mathrm{IC}_{50}\right)$ value detected in Section 2.1.1. 


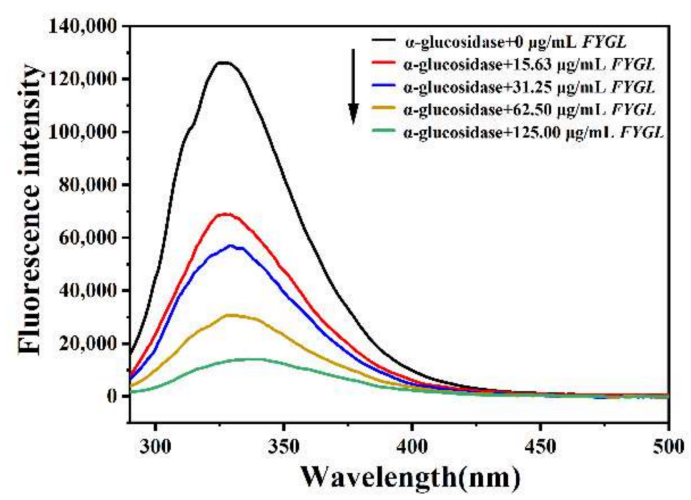

(A)

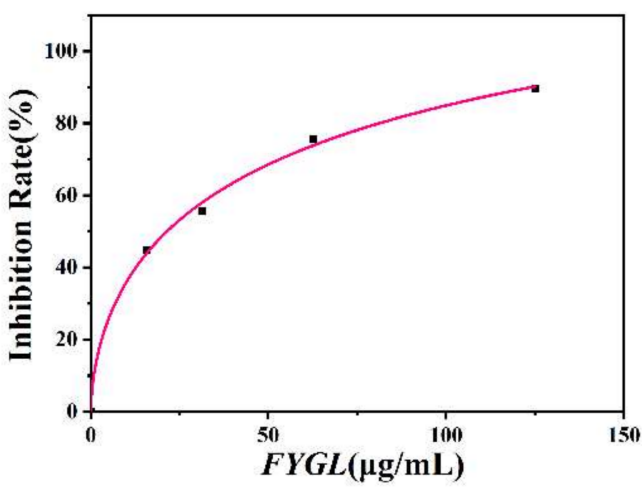

(B)

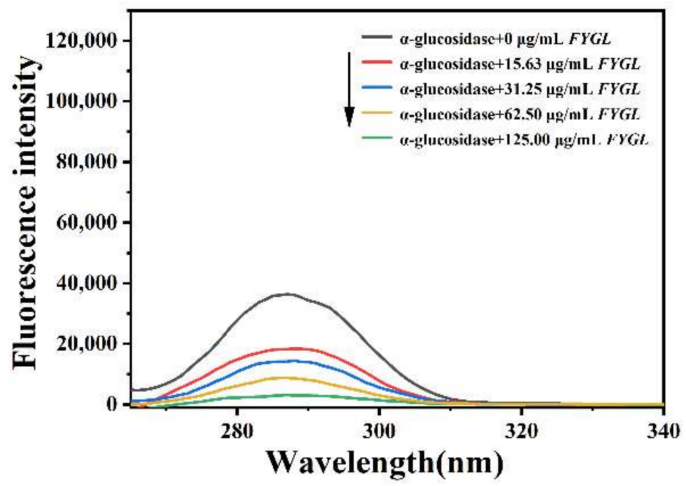

(D)

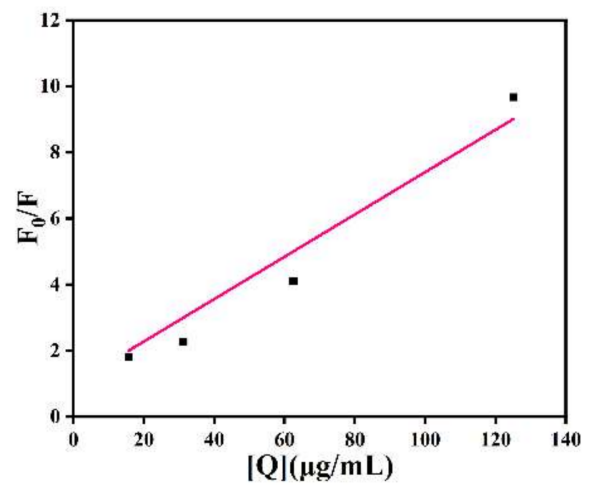

(C)

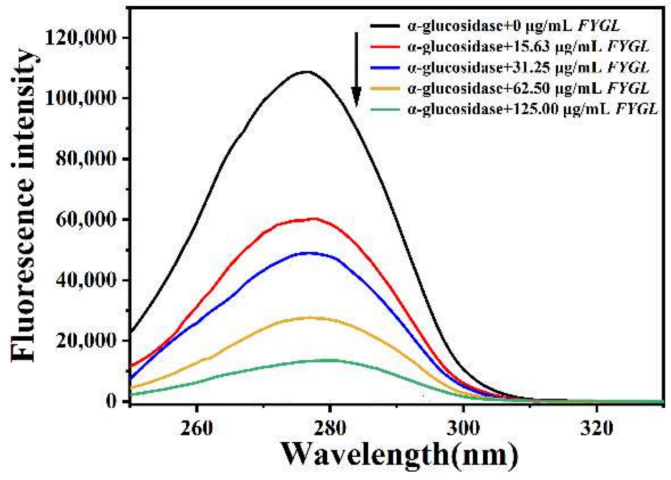

(E)

Figure 3. (A) Fluorescence spectra of $\alpha$-glucosidase effected by FYGL. (B) The quench rate of fluorescence intensity of $\alpha$-glucosidase effected by FYGL at maximum emission wavelength of $326 \mathrm{~nm}$. (C) Stern-Volmer curve showing dependence of $\frac{F_{0}}{F}$ on concentration of quencher FGYL. (D,E) Synchronous fluorescence spectra of $\alpha$-glucosidase with $\Delta \lambda=15 \mathrm{~nm}$ and $60 \mathrm{~nm}$ for tyrosine residue and tryptophan residue, respectively.

Fluorescence quenching generally has two types of model, static and dynamic. The former is induced by the formation of a complex without fluorescence between quencher and fluorophore, while the latter is induced by the collision between molecules, leading to the fluorescence decreasing. To investigate the fluorescence quenched model of $\alpha$ - 
glucosidase effected by FYGL, the fluorescence intensities at the maximum fluorescence emission wavelength were analyzed using the Stern-Volmer equation, Equation (4) [34]:

$$
\frac{F_{0}}{F}=1+K_{q} \tau_{0}[\mathrm{Q}]
$$

where $F_{0}$ and $F$ represent the fluorescence intensities in the absence and presence of FYGL, respectively; $K_{q}$ is the fluorescence quenching rate constant of $\alpha$-glucosidase; $\tau_{0}$ is the average lifetime of $\alpha$-glucosidase without the quencher of FYGL; and [Q] is the concentration of FYGL.

The fluorescence quenching rate constant $K_{q}$ can reflect the quenching model. If $K_{q}$ were much higher than $2.0 \times 10^{10} \mathrm{~L} \mathrm{~mol}^{-1} \mathrm{~s}^{-1}$, which is the maximum collision rate constant for all of the quenching agents that collide with biological macromolecules [35], the fluorescence quenching model would be thought to be a static one. Based on the Stern-Volmer equation (Equation (4)), where the average lifetime $\tau_{0}$ of a fluorophore is $10^{-8} \mathrm{~s}$ [36], $K_{q}$ was $1.7 \times 10^{18} \mathrm{~L} \mathrm{~mol}^{-1} \mathrm{~s}^{-1}$, calculated from the slope of the linear curve shown in Figure 3C, implying that the fluorescence quenching model of $\alpha$-glucosidase effected by FYGL was dominantly a static one, which was consistent with the competitivedominant inhibitory manner of FYGL, suggesting that a FYGL- $\alpha$-glucosidase complex was formed.

\subsubsection{Synchronous Fluorescence Spectroscopy of $\alpha$-Glucosidase Effected by FYGL}

Synchronous fluorescence technology can make the overlapped spectra highly sensitive and resolved. It can detect the changes in the surrounding microenvironment of, for example, tyrosine and tryptophan residues in proteins [32]. Figure 3D,E show the effect of FYGL on the synchronous fluorescence spectra of $\alpha$-glucosidase. The $\Delta \lambda$ between the excitation and emission wavelengths was set to 15 and $60 \mathrm{~nm}$ to reveal the spectroscopic characteristics of tyrosine (Figure 3D) and tryptophan residues (Figure 3E), respectively [37]. The fluorescence intensity of tryptophan residues was stronger than that of tyrosine. FYGL quenched the fluorescence intensity of those two residues dose-dependently, and the quenching rate was faster for tryptophan than for tyrosine.

Overall, FYGL could bind with $\alpha$-glucosidase to form FYGL- $\alpha$-glucosidase complex and induce structural changes of $\alpha$-glucosidase, resulting in the fluorescence quenching of amino acid residues. It has been reported that Asp215, 69, 352, Phe178, Val216, Glu411, Tyr72, 158, His112, Asn350, Gln353, and Arg442 are important amino acid residues in the catalytic center of $\alpha$-glucosidase [37]. Some natural products, such as phloretin, can directly bind to Asp215, Arg442, and Gln353 residues in the active site of $\alpha$-glucosidase and thereby inhibit its activity [37]. While some natural $\alpha$-glucosidase inhibitors, such as tannic acid, do not bind to the active site of $\alpha$-glucosidase, they bind to the nearby active sites and induce the conformation change of the enzyme [28]. Therefore, we speculate that FYGL could either bind to the active site of $\alpha$-glucosidase or the nearby ones, inducing the structure and conformation changes of $\alpha$-glucosidase and preventing the substrate entering the active site of the enzyme, thereby leading to the decrease of $\alpha$-glucosidase activity.

\subsection{Anti-Oxidative Capacity of FYGL}

The anti-oxidative capacity of FYGL was evaluated for its ability to scavenge ABTS ${ }^{+\bullet}$ (2,2'-azino-bis (3-ethylbenzothiazoline-6-sulphonic acid cation radicals) and reduce $\mathrm{Fe}^{3+}$ ions. Trolox was used as the positive control. Figure $4 \mathrm{~A}$ shows the $\mathrm{ABTS}^{+\bullet}$ scavenging ability of FYGL. Logistic fitting analysis for curves showed that the $\mathrm{IC}_{50}$ values of FYGL and Trolox were $22.33 \mu \mathrm{g} / \mathrm{mL}$ and $10.18 \mu \mathrm{g} / \mathrm{mL}$, respectively. Although the ability of FYGL scavenging $\mathrm{ABTS}^{+\bullet}$ was slightly lower than that of Trolox, FYGL could scavenge most of $\mathrm{ABTS}^{+\bullet}$ at higher concentration, implying that FYGL has strong anti-oxidative activity against free radicals. Figure $4 \mathrm{~B}$ shows the power of FYGL reducing $\mathrm{Fe}^{3+}$ ions. Results showed that Trolox had much stronger reductive capacity for $\mathrm{Fe}^{3+}$ than FYGL, while the latter was much milder. 


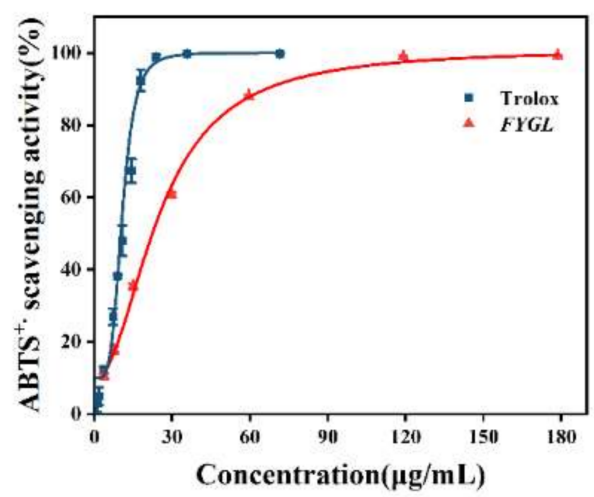

(A)

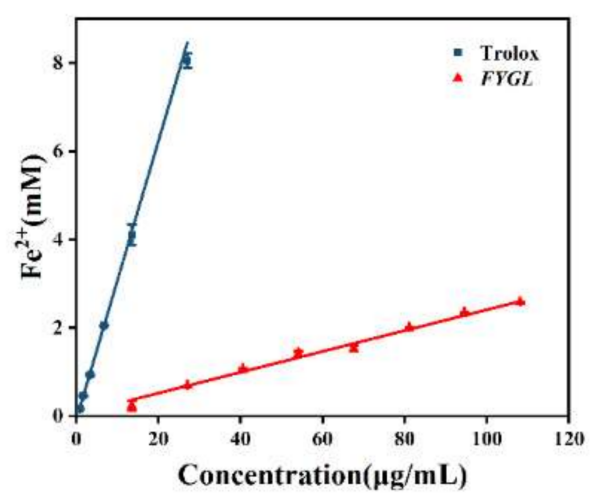

(B)

Figure 4. (A) $\mathrm{ABTS}^{+\bullet}$ scavenging activity and (B) ferric-reducing power of FYGL. Trolox was used as the positive control. Each value represents the mean $\pm \mathrm{SD}(n=3)$.

Overall, FYGL had strong radical-scavenging and mild ferric-reducing power; the electron donating moieties of FYGL, such as galactose and cystine, might contribute to this ability. In addition, the biological activities of natural products are highly related to the sites of glycosidic linkages and protein content in their chemical composition. For instance, a neutral heteropolysaccharide from Lycium barbarum containing mannose, galactose, and arabinose, linked by 1-3-, 1-2-, and 1-6-glycosidic linkages, was reported to have antioxidative activity [38]. A protein-bound heteropolysaccharide from tea was reported to have anti-oxidative activity with dependence on its protein content [39]. FYGL has the glycosidic linkages of 1-3-, 1-2-, and 1-6- and protein, which might be responsible for its anti-oxidative activity.

\subsection{Anti-Glycation Effect of FYGL}

2.3.1. Inhibition of FYGL on Non-Enzymatic Protein Glycation in BSA-Fructose Model Inhibition of FYGL on Three Stages of Glycation

The BSA-fructose model was used to evaluate the inhibitory effect of FYGL on nonenzymatic protein glycation in vitro. Aminoguanidine (AG) was used as the positive control. The process of non-enzymatic glycation of protein includes three stages: early stage, middle stage, and end stage. At the early stage, the amino groups in the proteins react with the carbonyl group in the reductive saccharides to form a Schiff base, which is unstable and prone to rearrangement to form relatively stable Amadori products; among them, fructosamine is the most representative one. At the middle stage, the Amadori products undergo dehydration, rearrangement, and other reactions to form highly reactive dicarbonyl compounds, such as the representatives of glyoxaldehydes and acetonaldehydes. At the end stage, the dicarbonyl compounds further react and crosslink with the free amino groups to form the complicated, stable, and irreversible complexes of advanced glycated end products (AGEs) [40]. For evaluating the capacity of anti-glycation at every stage of the non-enzymatic glycation process, the representative products can be detected by spectroscopy.

Figure $5 \mathrm{~A}$ shows the inhibition rate of fructosamine generated in the early stage in the BSA-fructose sample incubated with FYGL or AG, measured by UV absorbance at $530 \mathrm{~nm}$ using nitrotetrazolium blue chloride (NBT) assay [41]. The results showed that FYGL and AG suppressed the generation of fructosamine in a dose-dependent manner. The inhibition rate was increased from $12.91 \%$ to $27.08 \%$ as the concentration of $F Y G L$ increased from 125 to $750 \mu \mathrm{g} / \mathrm{mL}$. The inhibition rate of AG (a positive control) was increased from $4.92 \%$ to $11.56 \%$ as the concentration of AG increased from 250 to $750 \mu \mathrm{g} / \mathrm{mL}$. Compared to AG, FYGL had a higher inhibitory effect on the early stage of glycation. Figure $5 \mathrm{~B}$ shows the inhibition rate of dicarbonyl compounds generated in the middle stage, measured by UV absorbance at $290 \mathrm{~nm}$ using Girard-T assay [42]. Results showed that FYGL and AG also 
decreased the generation of dicarbonyl compounds in a dose-dependent manner. The inhibition rate increased from $13.31 \%$ to $31.49 \%$ as FYGL concentration increased from 125 to $750 \mu \mathrm{g} / \mathrm{mL}$ and the inhibition rates of AG from $15.19 \%$ to $22.96 \%$ as AG concentration increased from 250 to $750 \mu \mathrm{g} / \mathrm{mL}$. FYGL exerted an inhibitory effect stronger than AG in the middle stage of glycation. Figure $5 \mathrm{C}$ shows the inhibition rate of AGEs generated in the end stage measured by fluorescence emission at $440 \mathrm{~nm}$ with excitation at $350 \mathrm{~nm}$ [43]. FYGL showed excellently inhibitory capacity on the generation of AGEs. The inhibition rates increased from $35.41 \%$ to $85.68 \%$ as the concentration of FYGL increased from 125 to $750 \mu \mathrm{g} / \mathrm{mL}$, and the generation of AGEs was almost completely suppressed at high concentration of FYGL.

As above, at FYGL concentration of $750 \mu \mathrm{g} / \mathrm{mL}$, the inhibition rates of FYGL on glycation at the three stages were $27.08 \%, 31.49 \%$, and $85.68 \%$, respectively, indicating that the anti-glycation of FYGL was the most efficient at the end stage in the process of non-enzymatic glycation, during which the stable and irreversible complexes were formed.

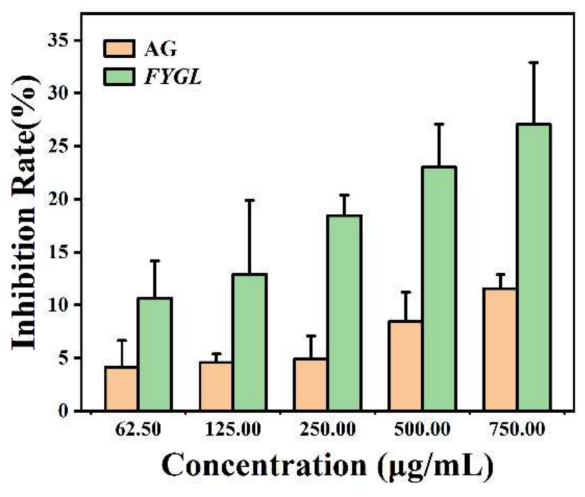

(A)

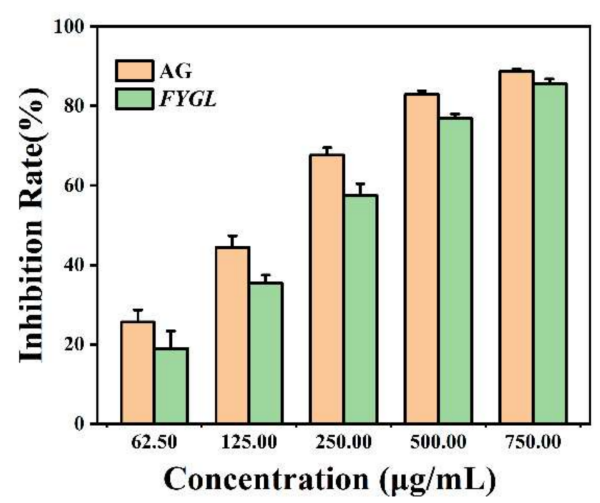

(C)

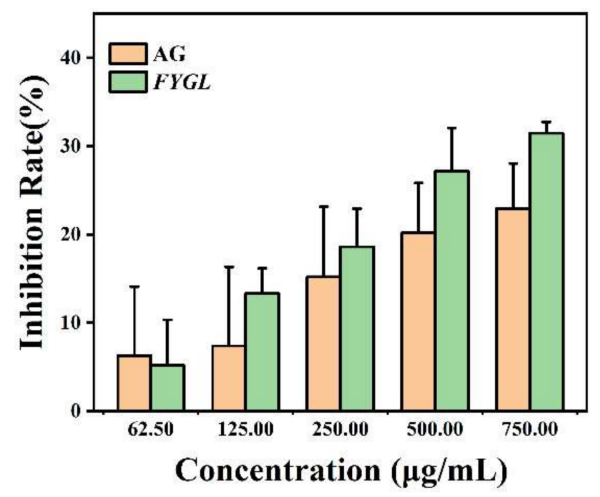

(B)

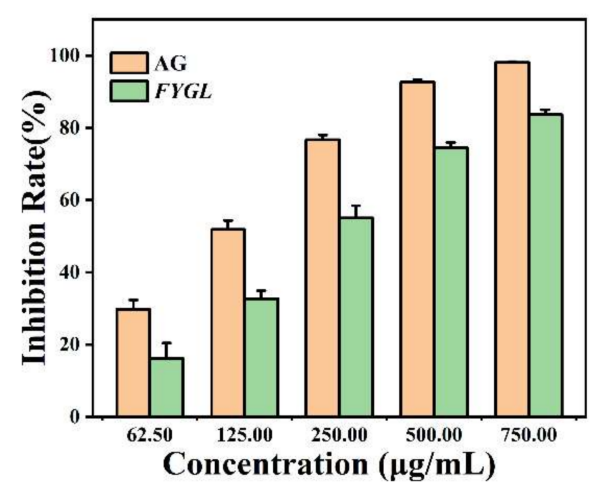

(D)

Figure 5. Cont. 


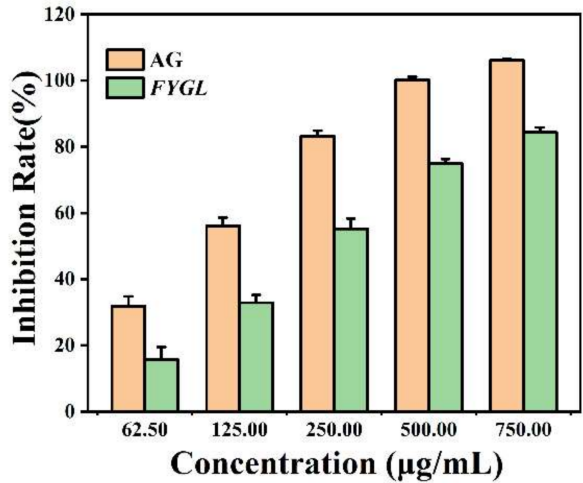

(E)

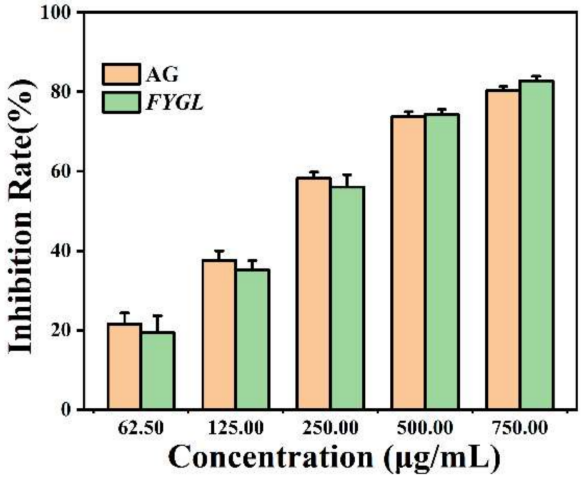

(F)

Figure 5. Effect of FYGL on the formation of glycation products in the bovine serum albumin (BSA)fructose model. (A) Inhibition rate of fructosamine generated in the early stage in BSA-fructose sample incubated with FYGL or aminoguanidine (AG), measured by UV absorbance at $530 \mathrm{~nm}$. (B) Inhibition rate of dicarbonyl compound generated in the middle stage, measured by UV absorbance at $290 \mathrm{~nm}$. (C) Inhibition rate of advanced glycation end products (AGEs) generated in the end stage, measured by fluorescence emission at $440 \mathrm{~nm}$ with excitation at $350 \mathrm{~nm}$. (D-F) Inhibition rates of formation of dityrosine, $\mathrm{N}^{\prime}$-formyl kynurenine, and kynurenine, respectively, measured by fluorescence at 415 , 434 , and $480 \mathrm{~nm}$ with excitation at 330, 325, and $365 \mathrm{~nm}$, respectively. Each value represents the mean $\pm \mathrm{SD}(n=3)$.

\section{Effect of FYGL on Protein Oxidation}

Protein glycation is accelerated by oxidation. Dityrosine, $\mathrm{N}^{\prime}$-formyl kynurenine, and kynurenine are iconic products of protein glycoxidation; they result from the oxidation of tryptophan and tyrosine residues [44]. Figure 5D-F show the inhibition impact of FYGL and AG on the formation of these three markers of protein glycoxidation in the BSA-fructose sample, detected by their intrinsic fluorescence at 415,434 , and $480 \mathrm{~nm}$ with excitation at 330, 325, and $365 \mathrm{~nm}$, respectively. A similar dose-dependent inhibition effect on three markers was observed, even though the inhibition rate of FYGL was slightly lower than that of AG. The results indicated that FYGL prevented the oxidation of tryptophan and tyrosine residues in BSA incubated with fructose. The outstanding anti-glycoxidation ability of FYGL also enhanced its anti-glycation capacity.

Inhibition of FYGL on Crosslinking and Aggregation of Amyloid Fibrillation

During glycation, amino acid residues in proteins, especially lysine and arginine residues, are modified by sugars, which induce the crosslinking and aggregation of the glycated proteins to ultimately form high-molecular-mass aggregates and amyloid-like fibrils in the later stages of glycation [45].

Formation of BSA $\beta$-amyloid fibrillation was determined herein by thioflavin T (ThT)labeled fluorescence assay. The greater the amyloid fibrillation, the higher the fluorescence intensity of ThT-labeled proteins. Figure 6A,B show the fluorescence spectra and the inhibition rate of amyloid fibrillation formed in the BSA-fructose sample incubated with FYGL or AG, respectively. Results showed that the fluorescence intensity was much higher in fructose-glycated BSA than that of pure BSA (Figure 6A), indicating the formation of aggregates of amyloid fibrils during glycation. Interestingly, the inhibitory rate of $F Y G L$ on aggregation increased in a dose-dependent manner, up to $69.28 \%$ at $750 \mu \mathrm{g} / \mathrm{mL}$, much higher than the $32.73 \%$ of $\mathrm{AG}$ at the same concentration.

The molecular mass of aggregates formed during glycation were evaluated by SDSPAGE. Figure $6 \mathrm{C}$ shows the SDS-PAGE gel of BSA and glycated BSA in the presence or absence of FYGL or AG under denaturing conditions. Results showed that pure BSA exhibited a clear single band at about $66 \mathrm{kDa}$; however, when BSA was glycated by fructose, 
a high-molecular-weight band was found. As shown in Figure 6D, the image intensity of the BSA band decreased after glycation, but FYGL markedly suppressed the decrease. Combined with the ThT-labeled fluorescence analysis, we concluded that FYGL inhibited protein crosslinking and aggregation during glycation.

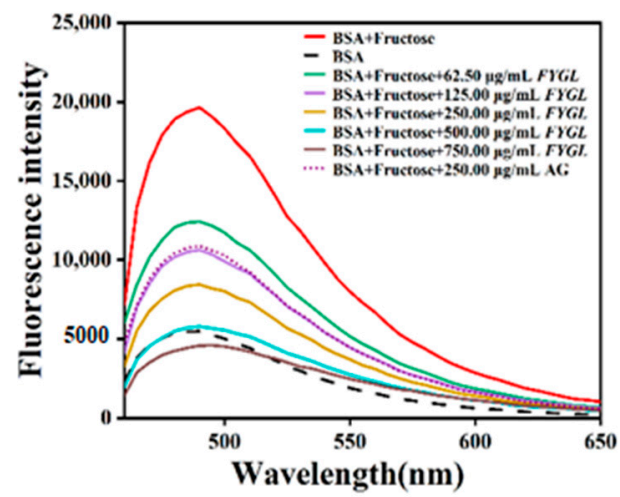

(A)

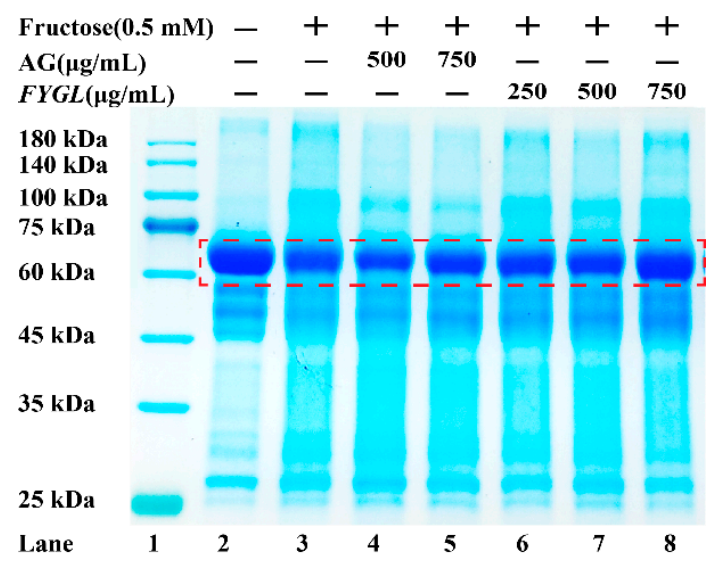

(C)

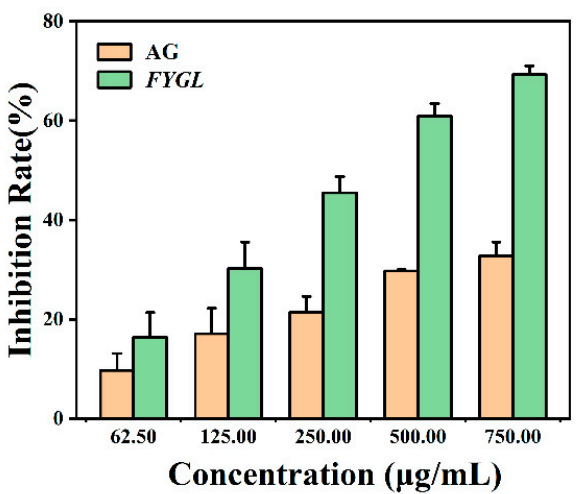

(B)

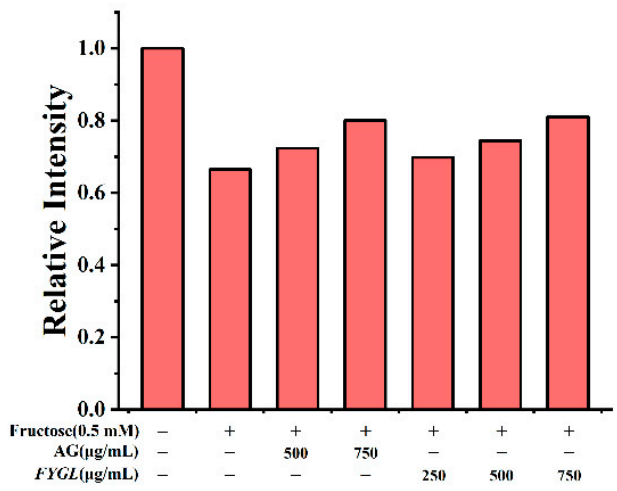

(D)

Figure 6. Effect of FYGL on crosslinking and aggregation in the BSA-fructose model. (A) The fluorescence spectra and (B) the inhibition rate on amyloid fibrillation formed in BSA-fructose sample incubated with FYGL or AG, based on the thioflavin T (ThT)-labeled fluorescence assay. Each value represents the mean \pm SD $(n=3)$. (C) SDS-PAGE bands of BSA and glycated BSA in the presence or absence of FYGL or AG under denaturing conditions. Lanes from left to right represent the protein markers (lane 1), pure BSA (lane 2), glycated BSA (lane 3), glycated BSA with AG (lane 4, 5), and glycated BSA with FYGL (lane 6-8). (D) The relative image intensity of pure BSA band in red rectangles in $(\mathbf{C})$.

\subsubsection{Preventative Effect of $F Y G L$ from BSA Glycation Induced by MGO}

Methylglyoxal (MGO) is one of the most reactive dicarbonyl intermediates generated in the middle stage of protein glycation. MGO covalently binds to functional groups of proteins and induces free radicals, leading to the formation of AGEs and crosslinked aggregates at the end stage of protein glycation. To identify the influence of FYGL on the end stage of protein glycation in the BSA-MGO model, the inhibition on AGEs was measured by intrinsic fluorescence and that on $\beta$-amyloid fibrillation by ThT-labeled fluorescence. As shown in Figure 7, FYGL also strongly inhibited the generation of AGEs and alleviated $\beta$-amyloid fibrillation in the MGO-induced glycation model.

It has been reported that free radicals and oxidation could accelerate AGE formation [46]. In this study, FYGL possessed abilities of scavenging free radicals and reduction. Therefore, FYGL strongly inhibited the generation of AGEs found in both BSA-fructose and BSA-MGO models, potentially leading to the alleviation of AGEs-related diabetic 
complications. Similarly, some natural products, such as Chinese bayberry (Myrica rubra) phenolics [47] and Gynura procumbens polysaccharides [48], have anti-glycation capacity due to their anti-oxidative activities.

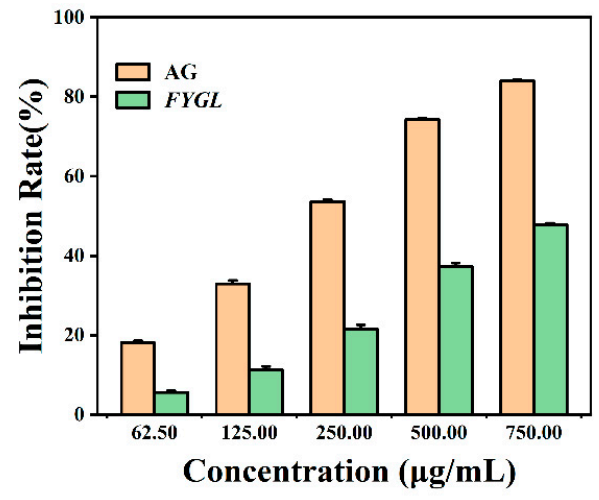

(A)

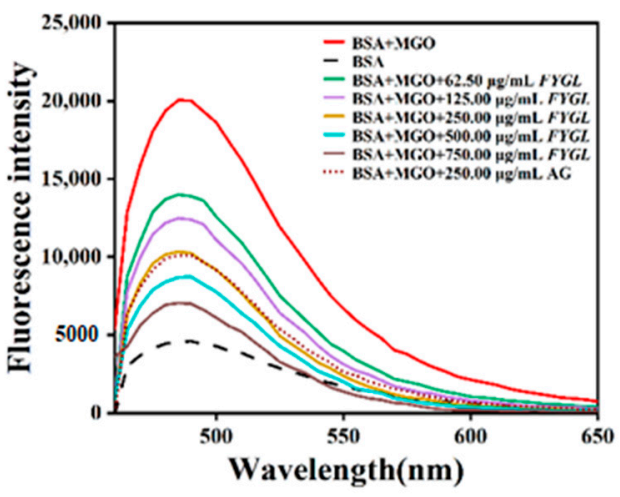

(B)

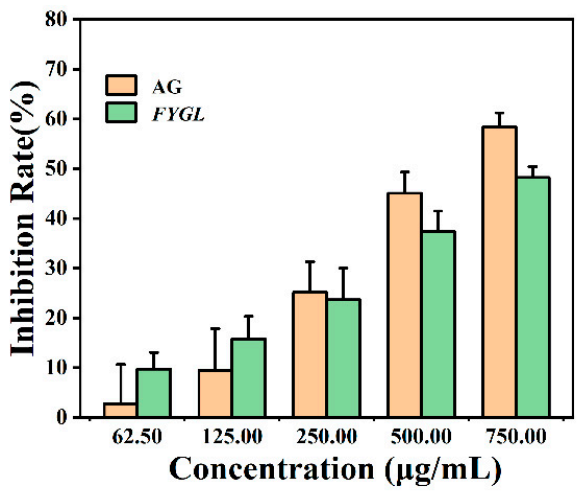

(C)

Figure 7. Effect of FYGL on glycation in BSA-methylglyoxal (MGO) model. (A) Inhibition rate of AGEs generated in the sample incubated with FYGL or AG, measured by intrinsic fluorescence. (B) Fluorescence spectra and (C) inhibition rate of amyloid fibrillation in the sample incubated with FYGL or AG, based on ThT-labeled fluorescence assay. Each value represents the mean $\pm \mathrm{SD}(n=3)$.

\subsubsection{Fluorescence Quenching of BSA by FYGL}

To reveal the interaction between FYGL and BSA in the anti-glycation function in the BSA-glycated model, the intrinsic fluorescence quenching of BSA was recorded. Figure 8 shows the fluorescence spectra of BSA effected by FYGL with excitation at $280 \mathrm{~nm}$. As the concentration of FYGL increased, the fluorescence intensity of BSA gradually decreased and the maximum fluorescence emission wavelength was red-shifted by $6 \mathrm{~nm}$, indicating that FYGL interacted with BSA to lead to an increase in the polarity and hydrophilicity in the micro-environment of tryptophan residues [49]. Similarly, based on the Stern-Volmer equation (Equation (4)), the fluorescence quenching rate constant $K_{q}$ was $1.3 \times 10^{18} \mathrm{~L}$ $\mathrm{mol}^{-1} \mathrm{~s}^{-1}$ from the inset graph in Figure 8, implying that the fluorescence quenching model was also a static one and a stable complex of FYGL-BSA was formed. Recently, some studies have reported that formation of non-covalent complexes with proteins can restrain the glycation $[47,49]$. Moreover, the hydrogen bonds played an important role to stabilize the non-covalent complex structure [50]. FYGL is a hydroxy-enriched proteoglycan and could possibly form a stable FYGL-BSA complex to hinder fructose or MGO from binding to active residues, such as lysine and arginine residues in BSA [47], thereby inhibiting BSA glycation. 


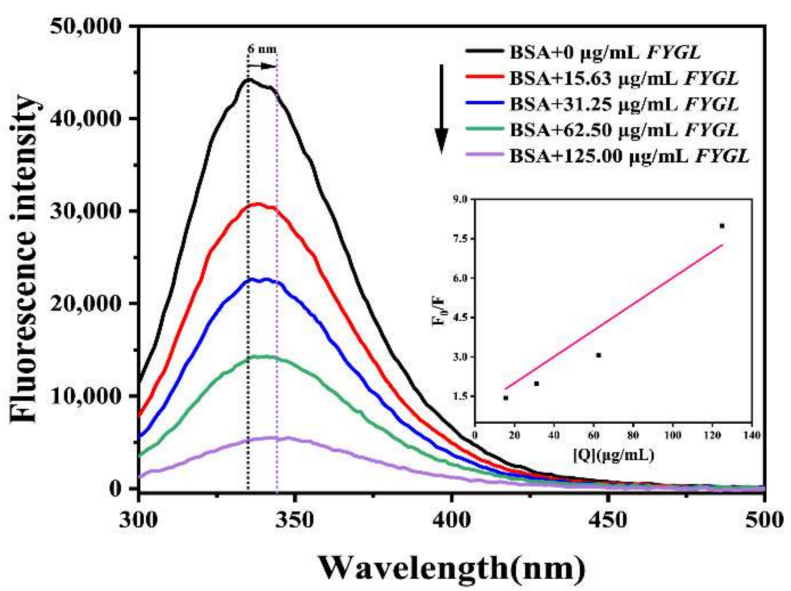

Figure 8. Fluorescence spectra of BSA effected by FYGL. The inset plot is the Stern-Volmer curve showing dependence of $\frac{F_{0}}{F}$ on concentration of quencher FGYL.

\subsection{Effect of FYGL on OSTT In Vivo}

We have previously demonstrated that FYGL significantly alleviated the fasting blood glucose (FBG) level, a major indicator of hyperglycemia, in $d b / d b$ mice [51]. In this study, we focused on the postprandial blood glucose (PBG) level, the other indicator of hyperglycemia, influenced by FYGL through oral sucrose tolerance test (OSTT). The normal and diabetic mice were randomly assigned into six groups, including normal group; model group; metformin group treated with $225 \mathrm{mg} / \mathrm{kg}$ metformin; FYGL-L group treated with 225 $\mathrm{mg} / \mathrm{kg}$ FYGL; FYGL-M group treated with $450 \mathrm{mg} / \mathrm{kg}$ FYGL and FYGL-H group treated with $900 \mathrm{mg} / \mathrm{kg}$ FYGL. Figure 9A,B show the anti-postprandial hyperglycemic effect of FYGL on sucrose-loaded normal and $d b / d b$ mice over $120 \mathrm{~min}$ with metformin as a positive reference. The results show that the peak values of blood glucose in each group appeared at approximately $30 \mathrm{~min}$ after oral administration of sucrose and then dropped. The blood glucose concentrations of $d b / d b$ mice (model group) remained higher than that of normal mice. For FYGL groups, the blood glucose values were lower than that of the model group after $30 \mathrm{~min}$, and that of the high-dose FYGL-H group was significantly lower, indicating that FYGL could efficiently reduce PBG. The AUC results in Figure 9B were consistent with those in Figure 9A. The results suggested that FYGL effectively alleviated sucrose-mediated PBG in $d b / d b$ mice, possibly because of the inhibition of $\alpha$-glucosidase activity.

\subsection{Effect of FYGL Treatment on Aortic Histopathology and AGE Accumulation In Vivo}

FYGL can alleviate the level of biochemical indexes, such as FBG, triglycerides, and total cholesterol, in STZ-induced diabetic SD rats [23]; these indexes are related to vascular injury and AGE accumulation. In this study, to evaluate the effect of FYGL treatment on diabetic vascular injury, H\&E staining was applied to observe the morphological changes of abdominal aortic tissues in normal and diabetic SD rats (Figure 10A). The grouping information was similar as Section 2.4, but dosages are for SD rats. In the normal group, both the intimal and medial layers of the H\&E-stained aorta showed orderly arrangement (in red), and the nuclei showed uniform distribution (in dark blue) without deformation and lesion. In the model group, both intimal and medial layers were disordered and thickened, while after oral treatment of FYGL and metformin (a positive drug), the aorta layers were orderly arranged with less deformation, and the nuclei were evenly distributed, indicating that FYGL could alleviate the vascular injury. 


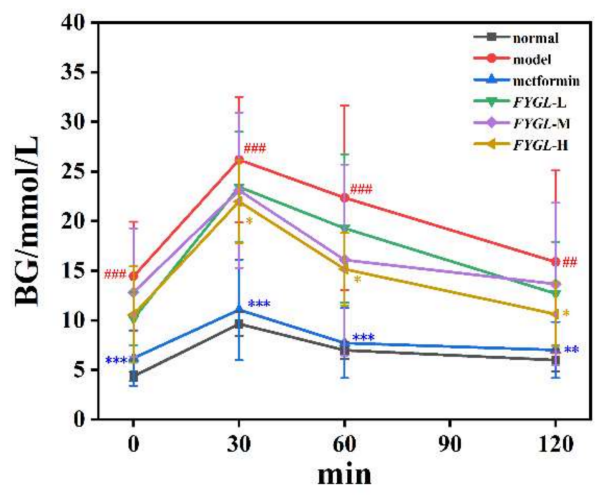

(A)

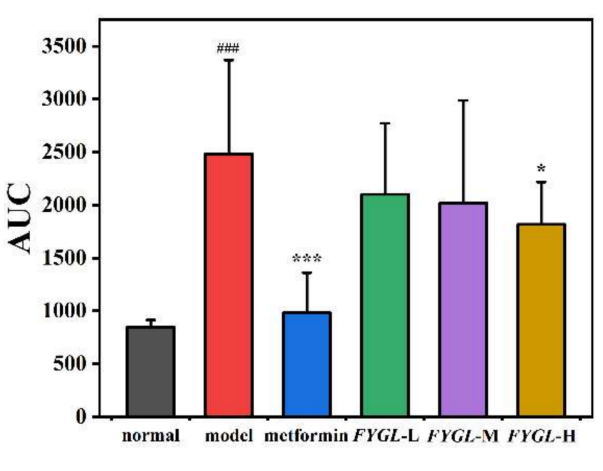

(B)

Figure 9. Postprandial blood glucose (PBG) affected by oral administration of FYGL in sucrose-loaded normal mice and diabetic mice. (A) PBG levels measured after oral administration of sucrose over $120 \mathrm{~min}$. (B) The value of the area under the curve (AUC) of each group calculated from the curve areas in (A). The values represent the mean \pm SD $\left(n=12 ;{ }^{\# \# \#} p<0.001\right.$ vs. normal, ${ }^{\#} p<0.01$ vs. normal, ${ }^{*} p<0.05$ vs. model, ${ }^{* *} p<0.01$ vs. model, ${ }^{* * *} p<0.001$ vs. model).

In addition, because AGE accumulation could result in the injury of aortic tissues, the expression of AGEs was measured in vivo by immunohistochemical analysis shown in Figure 10B,C. The results showed that the AGE expression (in brown) was greatly enhanced in the model group compared to the normal group, while it was significantly alleviated in a dose-dependent manner after FYGL treatment, possibly due to FYGL preventing protein crosslinking and fibrillation, thereby preventing injury of the vasculature. Furthermore, AGEs can activate the AGE-RAGE pathway, resulting in oxidative stress and inflammation [52], while FYGL could potentially inhibit activation of the AGE-RAGE pathway and alleviate related diabetic complications. 

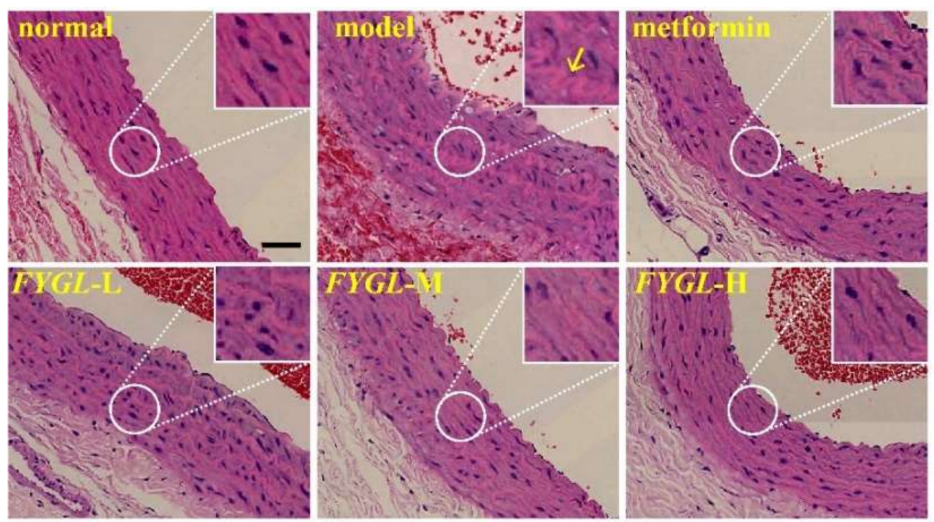

(A)

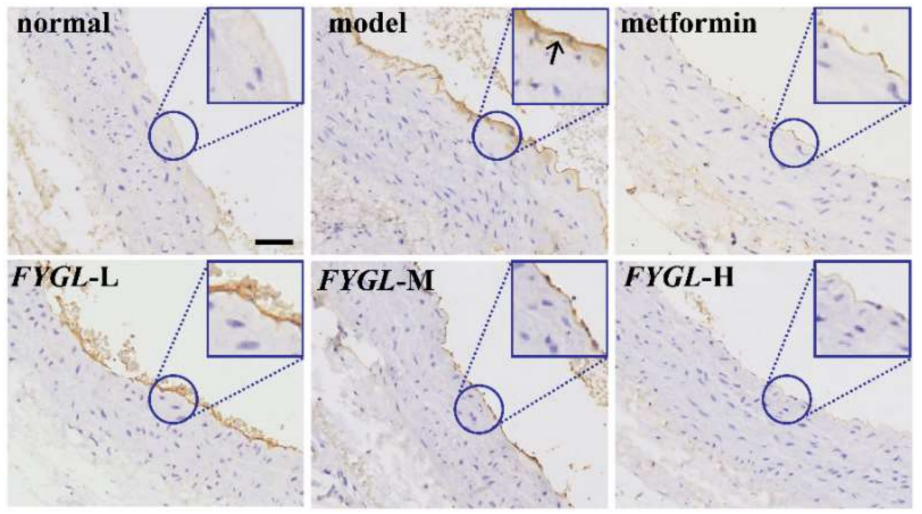

(B)

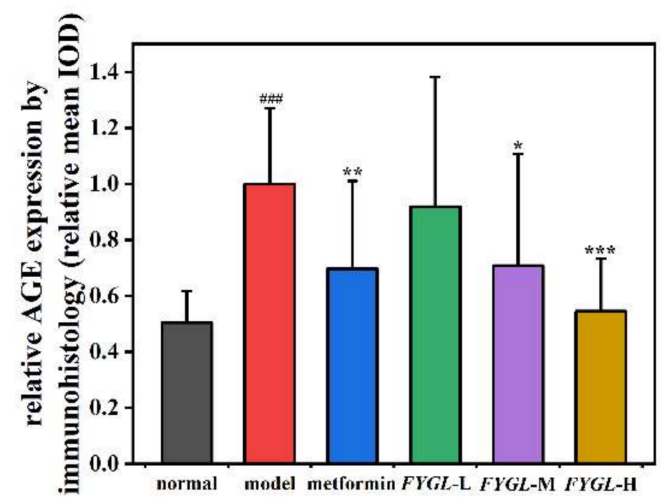

(C)

Figure 10. Histopathology and AGE accumulation in aorta tissues in vivo. (A) Representative images of H\&E-stained aorta tissues, magnification $100 \times$. The yellow arrow shows the aorta layers (in red) severely disordered and the nuclei (in dark blue) unevenly distributed in model group. (B) The immunohistochemical analysis of AGEs in the aorta tissues, magnification $100 \times$. The black arrow shows the heave AGE accumulation (in brown) in model group. The scale bar is $50 \mu \mathrm{m}$. The typical images in (A,B) were enlarged by four times for clear observation. (C) Quantitative analysis of AGE accumulation in the aorta by Image-Pro Plus 6.0 software. The values represent the mean $\pm \operatorname{SD}(n=6$; \#\#\# $p<0.001$ vs. normal, ${ }^{*} p<0.05$ vs. model, ${ }^{* *} p<0.01$ vs. model, ${ }^{* *} p<0.001$ vs. model). 


\section{Materials and Methods}

\subsection{Materials}

Fruiting bodies of Ganoderma lucidum grown in north-eastern China were purchased from Leiyunshang Pharmaceutical Co. Ltd. (Shanghai, China). FYGL was obtained from Ganoderma lucidum as previously described [20], and Figure S1 shows its NMR spectrum. Yeast $\alpha$-glucosidase (EC 3.2.1.20), purchased from Sigma-Aldrich Co. (St. Louis, MO, USA), was prepared in sodium phosphate buffer $(0.1 \mathrm{M}, \mathrm{pH} 6.8)$. Metformin, acarbose, aminoguanidine (AG), $p$-nitrophenyl- $\alpha$-D-glucopyranoside ( $p$ NPG), nitrotetrazolium blue chloride (NBT), Girard-T reagent, thioflavin T (ThT), and methylglyoxal (MGO) were purchased from Aladdin Chemical Co. (Shanghai, China). Fructose, sucrose, and trichloroacetic acid (TCA) were purchased from Sinopharm Chemical Reagent Co., Ltd. (Shanghai, China). The antibody of AGEs was purchased from Abcam (Cambridge, MA, USA). Bovine serum albumin (BSA) was obtained from Yeasen biotechnology Co., Ltd. (Wuhan, China). All other chemicals and solvents were of analytical quality, and fresh ultrapure water was used in all of the experiments.

\subsection{Anti-Postprandial Hyperglycemia Assay In Vitro}

\subsubsection{Inhibition of $\alpha$-Glucosidase Activity}

The $\alpha$-glucosidase inhibition potency of FYGL was evaluated using the method reported by Han [37], with minor modifications. Briefly, the $\alpha$-glucosidase enzyme activity was measured by adding $50 \mu \mathrm{L}$ of $0.07 \mathrm{unit} / \mathrm{mL} \alpha$-glucosidase from S. cerevisiae and $50 \mu \mathrm{L}$ of $1.0 \mathrm{mM}$ pNPG in $0.1 \mathrm{M}$ phosphate buffer solution ( $\mathrm{pH}$ 6.8), with or without FYGL, and acarbose as a positive control. The UV absorbance at $405 \mathrm{~nm}$ of the mixed solution was recorded every $60 \mathrm{~s}$ at $37^{\circ} \mathrm{C}$ with a microplate reader. The enzyme activity was presented as the change in the absorbance per minute, which was the slope of the obtained curve. The inhibitory effect of FYGL or acarbose was defined as Equation (5):

$$
\text { Inhibitory activity }(\%)=\frac{\mathrm{R}_{\text {blank }}-\mathrm{R}_{\text {inhibitor }}}{\mathrm{R}_{\text {blank }}} \times 100
$$

where $\mathrm{R}_{\text {inhibitor }}$ is the slope of the reaction kinetics curve obtained by the reaction of inhibitor of FYGL or acarbose with substrate, and $\mathrm{R}_{\text {blank }}$ is the slope without inhibitor. To evaluate the inhibitory potency of the inhibitors, the concentrations of FYGL and acarbose leading to the loss of $50 \% \alpha$-glucosidase activity $\left(\mathrm{IC}_{50}\right)$ was calculated based on the logistic analysis of the curve of inhibition rate vs. concentration [53].

\subsubsection{Inhibition Model on $\alpha$-Glucosidase}

To investigate the inhibition model of FYGL on $\alpha$-glucosidase, different concentrations of FYGL were individually added to the mixtures of $50 \mu \mathrm{L}$ of $\alpha$-glucosidase within concentrations of $0.035-0.210 \mathrm{unit} / \mathrm{mL}$ and $50 \mu \mathrm{L}$ of $p \mathrm{NPG}$ within concentrations of $0.5-1.5 \mathrm{mM}$. The absorbance of the reaction mixture was recorded every $60 \mathrm{sec}$ at $405 \mathrm{~nm}$. The dependence of enzymatic rate $v$ vs. $\alpha$-glucosidase concentration at different FYGL concentrations was used to determine the inhibition model. The $v$ value was the change in absorbance at $405 \mathrm{~nm}$ per min. The inhibition kinetics parameters were analyzed using double-reciprocal plots (Lineweaver-Burk plots) of the inhibition rate $v$ vs. substrate concentration, and the plots of the slopes and y-intercepts vs. FYGL concentration.

\subsubsection{Intrinsic Fluorescence Quenching Assay of $\alpha$-Glucosidase}

To further investigate the interaction between FYGL and $\alpha$-glucosidase, the intrinsic fluorescence of $\alpha$-glucosidase was recorded after incubation with FYGL. $\alpha$-Glucosidase $(0.05 \mathrm{mg} / \mathrm{mL})$ was pretreated with various concentrations of FYGL $(15.63-125.00 \mu \mathrm{g} / \mathrm{mL})$ for $10 \mathrm{~min}$ at room temperature. Then, the intrinsic fluorescence spectra of $\alpha$-glucosidase were recorded by FLS1000 (Edinburgh Instruments, Livingston, UK) at emission wavelengths in the range of 300-500 nm with an excitation wavelength at $280 \mathrm{~nm}$ at room 
temperature. The excitation and emission bandwidths were both set to $1.0 \mathrm{~nm}$. The fluorescence intensities of $\alpha$-glucosidase affected by FYGL at the maximum fluorescence emission wavelength were analyzed using the Stern-Volmer equation.

The synchronous fluorescence spectroscopy is a novel technology which can sensitively identify the fluorescence spectrum of different amino residues in protein by changing the interval wavelength $(\Delta \lambda)$ between excitation and emission [32]. Herein, the synchronous fluorescence spectra were recorded at $\Delta \lambda$ of 15 and $60 \mathrm{~nm}$ to characterize the fluorescence of tyrosine and tryptophan, respectively. The excitation and emission slit widths were both set to $1.0 \mathrm{~nm}$.

\subsection{Anti-Oxidative Assay In Vitro}

To investigate the anti-oxidative capacity of FYGL, the scavenging activity of a radical cation of $\mathrm{ABTS}^{+\bullet}$ and the reduction power were investigated.

The ability of FYGL to scavenge $\mathrm{ABTS}^{+\bullet}$ was assayed by a total antioxidant capacity assay kit of ABTS (Beyotime Biotechnology Development Co., Ltd., Shanghai, China). Briefly, $200 \mu \mathrm{L}$ of fresh ABTS radical cation solution was mixed with $10 \mu \mathrm{L}$ FYGL at room temperature for $6 \mathrm{~min}$, and then the absorbance was recorded at $734 \mathrm{~nm}$. Trolox was used as a positive control. The $\mathrm{ABTS}^{+\bullet}$ scavenging activity was calculated using Equation (6):

$$
\text { Scavenging activity }(\%)=\frac{\mathrm{OD}_{\text {blank }}-\mathrm{OD}_{\text {test }}}{\mathrm{OD}_{\text {blank }}} \times 100
$$

where $\mathrm{OD}_{\text {test }}$ represents the optical density (OD) of the mixture with FYGL or Trolox and OD blank denotes that of blank solution without FYGL or Trolox.

The reduction power was tested using a total antioxidant capacity assay kit with $\mathrm{Fe}^{3+}$ (Beyotime Biotechnology Development Co. Ltd., Shanghai, China). Briefly, $180 \mu \mathrm{L}$ of ferric-tripyridyltriazine solution was mixed with $5 \mu \mathrm{L} \mathrm{FYGL}$ at $37{ }^{\circ} \mathrm{C}$ for $5 \mathrm{~min}$, and then the absorbance was recorded at $593 \mathrm{~nm}$. Trolox was used as the positive control. The reduction power of the samples was expressed as $\mathrm{mmol} \mathrm{Fe}{ }^{2+}$. The higher the content of $\mathrm{Fe}^{2+}$, the stronger the reduction capacity of FYGL.

\subsection{Anti-Glycation Assay In Vitro}

\subsubsection{BSA-Fructose Model of Non-Enzymatic Protein Glycation}

The BSA-fructose model was established based on the work reported by Wang [54] with minor modification to evaluate the inhibitory effect of FYGL on the glycation process. AG (aminoguanidine) was used as the positive control. BSA $(20.0 \mathrm{mg} / \mathrm{mL})$ and different concentrations of FYGL or AG were dissolved in potassium phosphate buffer ( $\mathrm{pH} 7.4$, $0.1 \mathrm{M}$ ) containing $0.02 \%$ sodium azide and pre-incubated for $30 \mathrm{~min}$ at room temperature, and then fructose $(0.5 \mathrm{M})$ was added and incubated at $50{ }^{\circ} \mathrm{C}$ for $24 \mathrm{~h}$. After incubation was terminated, the sample was stored at $-20^{\circ} \mathrm{C}$ for further use.

\section{NBT Assay for Fructosamine}

The content of fructosamine in the BSA-fructose sample was analyzed according to the NBT (nitrotetrazolium blue chloride) method reported by Johnson [41], during which NBT could be reduced by fructosamine to form a colored formazan with strong UV absorption at $530 \mathrm{~nm}$. BSA-fructose solution and $0.3 \mathrm{mM}$ NBT solution were incubated at room temperature for $15 \mathrm{~min}$ and then transferred to 96-well plates; UV absorbance of the mixture solution was recorded at $530 \mathrm{~nm}$ to quantify the concentration of fructosamine. The inhibitory effect of FYGL was determined using Equation (7):

$$
\text { Inhibitory rate }(\%)=\frac{\mathrm{OD}_{\text {blank }}-\mathrm{OD}_{\text {test }}}{\mathrm{OD}_{\text {blank }}} \times 100
$$

where $\mathrm{OD}_{\text {test }}$ represents the OD of the sample with FYGL or AG and OD blank denotes that of blank solution without FYGL or AG. 
Girard-T Assay for Dicarbonyl Compound

The content of dicarbonyl compounds in the BSA-fructose sample was analyzed according to the Girard-T assay reported by Wells-Knecht [42], in which Girard-T reagent can react with dicarbonyl compound to form an addition product with strong absorption at $290 \mathrm{~nm}$. In brief, BSA-fructose solution, 0.5 M Girard-T reagent, and 0.5 M sodium formate solution were mixed at room temperature for $1 \mathrm{~h}$. The UV absorbance of the mixture solution was recorded at $290 \mathrm{~nm}$ to determine the dicarbonyl compound concentration. The inhibitory effect of FYGL was calculated using Equation (7).

\section{Fluorescence Assay for Generated AGEs and Oxidation Products}

The contents of AGEs produced in the BSA-fructose samples were analyzed by fluorescence at $440 \mathrm{~nm}$ with excitation at $350 \mathrm{~nm}$ [43]. In addition, the representative protein oxidation products of dityrosine, $\mathrm{N}$-formyl kynurenine, and kynurenine were also measured by fluorescence at 415, 434, and $480 \mathrm{~nm}$ with excitation at 330, 325, and $365 \mathrm{~nm}$, respectively [55]. The related inhibition rate was calculated using Equation (8):

$$
\text { Inhibitory rate }(\%)=\frac{F_{0}-F}{F_{0}} \times 100
$$

where $F_{0}$ represents the fluorescence intensity without $F Y G L$ or AG and $F$ represents that with FYGL or AG.

ThT-Based Fluorescence Assay for $\beta$-Amyloid Protein Aggregate

Thioflavin $\mathrm{T}$ (ThT) fluorescence would increase if ThT interacted with $\beta$-amyloid protein aggregate; therefore, it was used to identify the amount of $\beta$-amyloid protein aggregates [56]. Glycated protein was incubated with $20 \mu \mathrm{g} / \mathrm{mL}$ ThT solution at $25^{\circ} \mathrm{C}$ for $60 \mathrm{~min}$. Then, the fluorescence spectra of the mixed solution were recorded at an emission wavelength range of 455-600 nm with excitation wavelength of $435 \mathrm{~nm}$, and the intensity was recorded at $485 \mathrm{~nm}$ for amount of $\beta$-amyloid protein aggregates.

\section{SDS-PAGE Assay for Protein Aggregation}

Protein molecular weight was analyzed via the SDS-PAGE method according to Eze [57]. The glycated protein samples were dissolved and denatured with loading buffer at $100{ }^{\circ} \mathrm{C}$ for $5 \mathrm{~min}$ after being centrifugated at $12,000 \mathrm{rpm}$ to obtain protein precipitate by adding TCA (trichloroacetic acid). Then, $10 \mu \mathrm{g}$ denatured protein was separated by SDS-PAGE with $10 \%$ gel. The SDS-PAGE gel was dyed with Coomassie Blue super-fast staining solution (Beyotime Biotechnology Development Co., Ltd., Shanghai, China) for $30 \mathrm{~min}$ and then decolorized overnight. The protein content of each band on the stained gel was semi-quantified using Image J software.

\subsubsection{BSA-MGO Model of Non-Enzymatic Protein Glycation}

To further assess the effect of FYGL on the end stage of glycation process, the BSAMGO model was established according to the literature with minor modifications [58]. The experiment procedure was similar to that of the BSA-fructose model, except that, afterwards, MGO $(5.0 \mathrm{mg} / \mathrm{mL})$ was added. The BSA-MGO sample was incubated at $37^{\circ} \mathrm{C}$ for $72 \mathrm{~h}$ in the dark. Then, the contents of AGEs and $\beta$-amyloid protein aggregate produced in the BSA-MGO samples were analyzed using the same method mentioned in Section 3.4.1.

\subsubsection{Intrinsic Fluorescence Quenching Assay of BSA}

To reveal the interaction between FYGL and BSA in the anti-glycation function in BSA-glycated models, the intrinsic fluorescence of BSA was recorded after incubation with FYGL, referring to the protocols reported by $\mathrm{Li}[59]$. BSA $(0.1 \mathrm{mg} / \mathrm{mL})$ was pretreated with various concentrations of FYGL $(15.63-125.00 \mu \mathrm{g} / \mathrm{mL})$ at $37^{\circ} \mathrm{C}$ for $2 \mathrm{~h}$, and then the intrinsic fluorescence spectra were detected at emission wavelengths in the range of $300-500 \mathrm{~nm}$, with excitation wavelength at $280 \mathrm{~nm}$ at room temperature. The excitation and 
emission bandwidths were both set to $3.0 \mathrm{~nm}$. The fluorescence intensities at the maximum fluorescence emission wavelength were analyzed using the same Stern-Volmer equation (Equation (2)).

\subsection{Animal Trial}

\subsubsection{OSTT in Mice}

Male, four-week-old, BKS normal mice and BKS- $d b(d b / d b)$ diabetic mice were purchased from Gempharmatech Co., Ltd., Nanjing, China. The animals were housed in the SPF Animal Experimental Center of Efficacy Evaluation, School of Pharmacy, Fudan University. Mice were free to access water and food in the house maintained at a temperature of $20-26{ }^{\circ} \mathrm{C}$ and humidity of $40-70 \%$ with $12 \mathrm{~h}$ light/dark cycle. All trials and the care of animals were conducted under the guidance of the Experimental Animal Ethics Committee of Fudan University. After 1 week of adaptation, blood was collected from the tail vein of each mouse, and the fasting blood glucose level was measured. Only animals with blood glucose concentration higher than $11.1 \mathrm{mM}$ were used as the diabetic model for the trials.

Normal and diabetic mice were randomly assigned into 6 groups, with 12 mice per group, and orally administrated the drugs. Six groups included: normal group (normal BKS mice treated with saline); model group (diabetic mice treated with saline); metformin group (mice treated with metformin, $225 \mathrm{mg} / \mathrm{kg}$ ); FYGL-L group (diabetic mice treated with a low dose of FYGL, $225 \mathrm{mg} / \mathrm{kg}$ ); FYGL-M group (diabetic mice treated with a medium dose of FYGL, $450 \mathrm{mg} / \mathrm{kg}$ ); and FYGL-H group (diabetic mice treated with a high dose of FYGL, $900 \mathrm{mg} / \mathrm{kg}$ ). The fasting blood glucose level was measured weekly. To identify the effect of FYGL on postprandial blood glucose (PBG) in vivo, an oral sucrose tolerance test (OSTT) was used to reflect PBG after the mice were treated with drugs for 8 weeks. The normal and diabetic mice were orally administered $2.5 \mathrm{~g} / \mathrm{kg}$ sucrose after $2 \mathrm{~h}$ of drugs or saline taken, and blood samples were collected from the tail vein at 0,30,60, and $120 \mathrm{~min}$. PBG concentration was determined using a Contour TS blood glucose meter (Bayer, Berlin, Germany). The area under the curve (AUC) of blood glucose value vs. time was calculated to quantitatively identify the PBG.

\subsubsection{Histopathology and Immunohistology of Aortic Tissues in Diabetic Rats}

Because the abdominal aortas from $d b / d b$ mice were very thin, it is difficult to observe their morphology and investigate the accumulation of AGEs affected by the drugs. The diabetic rats were used for this purpose.

Male, four-week-old, SD rats were purchased from Shrek Laboratory Animal Co., Ltd., Shanghai China. The animals were housed in the same surroundings as Section 3.5.1. After 1 week of adaptation, all rats were randomly assigned either to a diabetic group or to a healthy normal group. The normal group rats were fed standard diet, while the rats in the diabetic group were fed a high-fat diet for 1 month. The diabetic group was intraperitoneally injected with a single dose of streptozotocin (STZ, $40 \mathrm{mg} / \mathrm{kg}$ of bodyweight; Sigma-Aldrich, St. Louis, MO, USA) to establish a diabetes mellitus (DM) model with blood glucose levels $>16.7 \mathrm{mmol} / \mathrm{L}$. The diabetic group was further divided into five groups, including model group; metformin group treated with $200 \mathrm{mg} / \mathrm{kg}$ metformin; FYGL-L group treated with $150 \mathrm{mg} / \mathrm{kg}$ FYGL; FYGL-M group treated with $300 \mathrm{mg} / \mathrm{kg}$ FYGL and FYGL-H group treated with $600 \mathrm{mg} / \mathrm{kg}$ FYGL.

After 7 weeks of drug treatment, all rats were anesthetized with pentobarbital and sacrificed. The abdominal aortas were quickly removed and immersed in $10 \%$ formalin for fixation. Then, these tissues were embedded in paraffin and cut into $4 \mu \mathrm{m}$ sections. The rehydrated sections were stained with hematoxylin-eosin (H\&E) for morphology observation [60]. Furthermore, immunohistology was used to evaluate the accumulation of AGEs in the tissues according to the methods of Wang, with modifications [61]. After the activity of endogenous peroxidase was blocked, the aorta sections were incubated with a rabbit anti-AGE antibody $(1: 1200)$ overnight at $4{ }^{\circ} \mathrm{C}$, and then the sections were treated by Ultra Sensitive ${ }^{\mathrm{TM}}$ SP kit (Maxim Biotechnology Development Co., Ltd., Fuzhou, China) 
according to the instructions. AGEs in tissue were colored brown by 3,3'-diaminobenzidine (DAB) and observed by NanoZoomer 2.0 HT scanner C12000 (Hamamatsu, Japan). The accumulation of AGEs was quantified by integrated optical density (IOD) using Image-Pro Plus 6.0 software.

\subsection{Statistical Analysis}

All experiments were repeated at least three times, and the results are expressed as mean \pm standard deviation (SD). Differences between groups were calculated by oneway ANOVA followed by the Bonferroni post hoc test, and $p<0.05$ was considered statistically significant.

\section{Conclusions}

This work investigated the effect of FYGL on $\alpha$-glucosidase activity and anti-nonenzymatic glycation in vitro. FYGL showed a reversible inhibition for $\alpha$-glucosidase activity in a mixed model. In addition, fluorescence spectroscopy also showed that the intrinsic fluorescence of $\alpha$-glucosidase was quenched by FYGL due to the formation of a FYGL- $\alpha$ glucosidase complex, resulting in the decrease in enzyme activity. During the anti-nonenzymatic glycation process, FYGL inhibited every stage of the glycation process and especially efficiently inhibited the production of AGEs and amyloid fibrillation generated in the end stage, possibly due to its anti-oxidative and scavenging radical capacities to prevent the glycoxidation and crosslinking of glycated BSA. Interestingly, in vivo, FYGL alleviated PBG levels demonstrated by OSTT and suppressed the accumulation of AGEs in aortic tissues, thereby reducing vascular injury. Taken together, these results provide support for the development of FYGL as an anti-diabetic agent and a novel $\alpha$-glucosidase and glycation inhibitor against diabetic complications.

Supplementary Materials: Supplementary materials are available online. Figure S1: ${ }^{1} \mathrm{H}-\mathrm{NMR}$ spectrum of FYGL in $\mathrm{D}_{2} \mathrm{O}$ solution.

Author Contributions: Y.Z.: methodology, investigation, formal analysis, writing — original draft. Y.P.: methodology, validation, investigation. J.L.: validation, investigation, resources. Z.Z.: methodology. Y.H.: methodology. H.Y.: conceptualization, funding acquisition. P.Z.: conceptualization, funding acquisition, writing-review and editing, project administration. All authors have read and agreed to the published version of the manuscript.

Funding: This research was funded by the National Natural Science Foundation of China (Nos. 21374022 and 81374032), National Health Commission of the People's Republic of China (No. 2017ZX09301006), Science and Technology Commission of Shanghai Municipality (No. 17401902700), and the Clinical Research Plan of SHDC (No. SHDC12019124).

Institutional Review Board Statement: The study was conducted in accordance with the Declaration of Helsinki and approved by the Ethics Committee of Fudan University (No. FE21038, 5 March 2021).

Informed Consent Statement: Not applicable.

Data Availability Statement: The data presented in this study are available within the article.

Conflicts of Interest: The authors declare no conflict of interest.

Sample Availability: Samples of FYGL are available from the authors.

\section{References}

1. Joshi, S.R.; Karne, R. Pre-diabetes, dysglycaemia and early glucose intolerance and vascular health. J. Assoc. Physicians India 2007, 55, 829-831.

2. Monnier, L.; Lapinski, H.; Colette, C. Contributions of fasting and postprandial plasma glucose increments to the overall diurnal hyperglycemia of type 2 diabetic patients: Variations with increasing levels of HbA(1c). Diabetes Care 2003, 26, 881-885. [CrossRef] [PubMed]

3. Song, P.; Onishi, A.; Koepsell, H.; Vallon, V. Sodium glucose cotransporter SGLT1 as a therapeutic target in diabetes mellitus. Expert Opin. Ther. Targets 2016, 20, 1109-1125. [CrossRef] [PubMed] 
4. Joshi, S.R.; Standl, E.; Tong, N.; Shah, P.; Kalra, S.; Rathod, R. Therapeutic potential of $\alpha$-glucosidase inhibitors in type 2 diabetes mellitus: An evidence-based review. Expert Opin. Pharmacother. 2015, 16, 1959-1981. [CrossRef] [PubMed]

5. Negre-Salvayre, A.; Salvayre, R.; Augé, N.; Pamplona, R.; Portero-Otín, M. Hyperglycemia and glycation in diabetic complications. Antioxid. Redox Signal. 2009, 11, 3071-3109. [CrossRef]

6. Goldin, A.; Beckman, J.A.; Schmidt, A.M.; Creager, M.A. Advanced glycation end products - sparking the development of diabetic vascular injury. Circulation 2006, 114, 597-605. [CrossRef]

7. Rhee, S.Y.; Kim, Y.S. The role of advanced glycation end products in diabetic vascular complications. Diabetes Metab. J. 2018, 42, 188-195. [CrossRef]

8. Potenza, A.M.; Gagliardi, S.; Nacci, C.; Carratu, R.M.; Montagnani, M. Endothelial dysfunction in diabetes: From mechanisms to therapeutic targets. Curr. Med. Chem. 2009, 16, 94-112. [CrossRef]

9. Puls, W. Pharmacology of glucosidase inhibitors. In Oral Antidiabetics; Kuhlmann, J., Puls, W., Eds.; Springer: Berlin/Heidelberg, Germany, 1996; pp. 497-534.

10. Bischoff, H. Pharmacology of alpha-glucosidase inhibition. Eur. J. Clin. Investig. 1994, 24, 3-10.

11. Aldini, G.; Vistoli, G.; Stefek, M.; Chondrogianni, N.; Grune, T.; Sereikaite, J.; Sadowska-Bartosz, I.; Bartosz, G. Molecular strategies to prevent, inhibit, and degrade advanced glycoxidation and advanced lipoxidation end products. Free Radic. Res. 2013, 47, 93-137. [CrossRef]

12. Luis Ros, J.; Francini, F.; Schinella, G.R. Natural products for the treatment of type 2 diabetes mellitus. Planta Med. 2015, 81, 975-994.

13. Dariya, B.; Nagaraju, G.P. Advanced glycation end products in diabetes, cancer and phytochemical therapy. Drug Discov. Today 2020, 25, 1614-1623. [CrossRef] [PubMed]

14. Bishop, K.S.; Kao, C.H.J.; Xu, Y.; Glucina, M.P.; Paterson, R.R.M.; Ferguson, L.R. From 2000 years of Ganoderma lucidum to recent developments in nutraceuticals. Phytochemistry 2015, 114, 56-65. [CrossRef] [PubMed]

15. Hsu, K.-D.; Cheng, K.-C. From nutraceutical to clinical trial: Frontiers in Ganoderma development. Appl. Microbiol. Biotechnol. 2018, 102, 9037-9051. [CrossRef]

16. Cheng, S.; Sliva, D. Ganoderma lucidum for cancer treatment: We are close but still not there. Integr. Cancer Ther. 2015, 14, $249-257$. [CrossRef]

17. Ma, H.-T.; Hsieh, J.-F.; Chen, S.-T. Anti-diabetic effects of Ganoderma lucidum. Phytochemistry 2015, 114, 109-113. [CrossRef]

18. Sun, L.-X.; Lin, Z.-B.; Lu, J.; Li, W.-D.; Niu, Y.-D.; Sun, Y.; Hu, C.-Y.; Zhang, G.-Q.; Duan, X.-S. The improvement of M1 polarization in macrophages by glycopeptide derived from Ganoderma lucidum. Immunol. Res. 2017, 65, 658-665. [CrossRef]

19. Kan, Y.; Chen, T.; Wu, Y.; Wu, J.; Wu, J. Antioxidant activity of polysaccharide extracted from Ganoderma lucidum using response surface methodology. Int. J. Biol. Macromol. 2015, 72, 151-157. [CrossRef]

20. Teng, B.-S.; Wang, C.-D.; Yang, H.-J.; Wu, J.-S.; Zhang, D.; Zheng, M.; Fan, Z.-H.; Pan, D.; Zhou, P. A protein tyrosine phosphatase 1B activity inhibitor from the fruiting bodies of Ganoderma lucidum (Fr.) Karst and its hypoglycemic potency on streptozotocininduced type 2 diabetic mice. J. Agric. Food Chem. 2011, 59, 6492-6500. [CrossRef]

21. Pan, D.; Wang, L.; Chen, C.; Hu, B.; Zhou, P. Isolation and characterization of a hyperbranched proteoglycan from Ganoderma lucidum for anti-diabetes. Carbohydr. Polym. 2015, 117, 106-114. [CrossRef]

22. Yu, F.; Teng, Y.; Yang, S.; He, Y.; Zhang, Z.; Yang, H.; Ding, C.-F.; Zhou, P. The thermodynamic and kinetic mechanisms of a Ganoderma lucidum proteoglycan inhibiting hIAPP amyloidosis. Biophys. Chem. 2022, 280, 106702. [CrossRef] [PubMed]

23. Teng, B.S.; Wang, C.D.; Zhang, D.; Wu, J.S.; Pan, D.; Pan, L.F.; Yang, H.J.; Zhou, P. Hypoglycemic effect and mechanism of a proteoglycan from Ganoderma lucidum on streptozotocin-induced type 2 diabetic rats. Eur. Rev. Med. Pharmacol. Sci. 2012, 16, 166-175. [PubMed]

24. Singh, V.P.; Bali, A.; Singh, N.; Jaggi, A.S. Advanced glycation end products and diabetic complications. Korean J. Physiol. Pharmacol. 2014, 18, 1-14. [CrossRef]

25. Schalkwijk, C.G.; Stehouwer, C.D.A. Methylglyoxal, a highly reactive dicarbonyl compound, in diabetes, its vascular complications, and other age-related diseases. Physiol. Rev. 2019, 100, 407-461. [CrossRef] [PubMed]

26. Wang, Y.; Zhang, G.; Pan, J.; Gong, D. Novel insights into the inhibitory mechanism of kaempferol on xanthine oxidase. J. Agric. Food Chem. 2015, 63, 526-534. [CrossRef]

27. Fang, Y.; Wang, S.; Wu, J.; Zhang, L.; Wang, Z.; Gan, L.; He, J.; Shi, H.; Hou, J. The kinetics and mechanism of $\alpha$-glucosidase inhibition by F5-SP, a novel compound derived from sericin peptides. Food Funct. 2017, 8, 323-332.

28. Huang, Q.; Chai, W.-M.; Ma, Z.-Y.; Ou-Yang, C.; Wei, Q.-M.; Song, S.; Zou, Z.-R.; Peng, Y.-Y. Inhibition of $\alpha$-glucosidase activity and non-enzymatic glycation by tannic acid: Inhibitory activity and molecular mechanism. Int. J. Biol. Macromol. 2019, 141, 358-368. [CrossRef]

29. Xiao, H.; Chen, C.; Li, C.; Huang, Q.; Fu, X. Physicochemical characterization, antioxidant and hypoglycemic activities of selenized polysaccharides from Sargassum pallidum. Int. J. Biol. Macromol. 2019, 132, 308-315. [CrossRef]

30. Wang, S.; Xie, X.; Zhang, L.; Hu, Y.-M.; Wang, H.; Tu, Z.-C. Inhibition mechanism of $\alpha$-glucosidase inhibitors screened from Artemisia selengensis Turcz root. Ind. Crops Prod. 2020, 143, 111941. [CrossRef]

31. Tian, G.C.; Sobotka-Briner, C.D.; Zysk, J.; Liu, X.D.; Birr, C.; Sylvester, M.A.; Edwards, P.D.; Scott, C.D.; Greenberg, B.D. Linear non-competitive inhibition of solubilized human gamma-secretase by pepstatin a methylester, L685458, sulfonamides, and benzodiazepines. J. Biol. Chem. 2002, 277, 31499-31505. [CrossRef] 
32. Peng, X.; Zhang, G.; Liao, Y.; Gong, D. Inhibitory kinetics and mechanism of kaempferol on $\alpha$-glucosidase. Food Chem. 2016, 190, 207-215. [CrossRef] [PubMed]

33. Xiao, H.Z.; Liu, B.G.; Mo, H.Z.; Liang, G.Z. Comparative evaluation of tannic acid inhibiting alpha-glucosidase and trypsin. Food Res. Int. 2015, 76, 605-610. [CrossRef]

34. Liu, M.C.; Jin, S.F.; Zheng, M.; Wang, Y.; Zhao, P.L.; Tang, D.T.; Chen, J.; Lin, J.Q.; Wang, X.H.; Zhao, P. Daunomycin-loaded superparamagnetic iron oxide nanoparticles: Preparation, magnetic targeting, cell cytotoxicity, and protein delivery research. $J$. Biomater. Appl. 2016, 31, 261-272. [CrossRef]

35. Xie, F.; Gong, S.; Zhang, W.; Wu, J.; Wang, Z. Potential of lignin from Canna edulis ker residue in the inhibition of $\alpha$-D-glucosidase: Kinetics and interaction mechanism merging with docking simulation. Int. J. Biol. Macromol. 2017, 95, 592-602. [CrossRef] [PubMed]

36. Zhang, G.; Wang, L.; Pan, J. Probing the binding of the flavonoid diosmetin to human serum albumin by multispectroscopic techniques. J. Agric. Food Chem. 2012, 60, 2721-2729. [CrossRef]

37. Han, L.; Fang, C.; Zhu, R.; Peng, Q.; Li, D.; Wang, M. Inhibitory effect of phloretin on $\alpha$-glucosidase: Kinetics, interaction mechanism and molecular docking. Int. J. Biol. Macromol. 2017, 95, 520-527. [CrossRef] [PubMed]

38. Yang, B.; Wang, J.; Zhao, M.; Liu, Y.; Wang, W.; Jiang, Y. Identification of polysaccharides from pericarp tissues of litchi (Litchi chinensis Sonn.) fruit in relation to their antioxidant activities. Carbohydr. Res. 2006, 341, 634-638. [CrossRef] [PubMed]

39. Chen, H.; Zhang, M.; Qu, Z.; Xie, B. Antioxidant activities of different fractions of polysaccharide conjugates from green tea (Camellia sinensis). Food Chem. 2008, 106, 559-563. [CrossRef]

40. Zeng, L.; Ding, H.F.; Hu, X.; Zhang, G.W.; Gong, D.M. Galangin inhibits alpha-glucosidase activity and formation of nonenzymatic glycation products. Food Chem. 2019, 271, 70-79. [CrossRef] [PubMed]

41. Johnson, R.N.; Metcalf, P.A.; Baker, J.R. Fructosamine: A new approach to the estimation of serum glycosylprotein. An index of diabetic control. Clin. Chim. Acta 1983, 127, 87-95. [CrossRef]

42. Wells-Knecht, K.J.; Zyzak, D.V.; Litchfield, J.E.; Thorpe, S.R.; Baynes, J.W. Identification of glyoxal and arabinose as intermediates in the autoxidative modification of proteins by glucose. Biochemistry 1995, 34, 3702-3709. [CrossRef] [PubMed]

43. Thornalley, P.J.; Rabbani, N. Detection of oxidized and glycated proteins in clinical samples using mass spectrometry-A user's perspective. Biochimica et Biophys. Acta (BBA)-Gen. Subj. 2014, 1840, 818-829. [CrossRef]

44. Ding, H.; Ni, M.; Zhang, G.; Liao, Y.; Hu, X.; Zhang, Y.; Gong, D. The inhibition of oleanolic acid on protein non-enzymatic glycation. LWT 2020, 125, 109253. [CrossRef]

45. Taghavi, F.; Habibi-Rezaei, M.; Amani, M.; Saboury, A.A.; Moosavi-Movahedi, A.A. The status of glycation in protein aggregation Int. J. Biol. Macromol. 2017, 100, 67-74. [CrossRef] [PubMed]

46. Sadowska-Bartosz, I.; Galiniak, S.; Bartosz, G. Kinetics of glycoxidation of bovine serum albumin by methylglyoxal and glyoxal and its prevention by various compounds. Molecules 2014, 19, 4880-4896. [CrossRef] [PubMed]

47. Zhang, Q.; Huang, Z.; Wang, Y.; Wang, Y.; Fu, L.; Su, L. Chinese bayberry (Myrica rubra) phenolics mitigated protein glycoxidation and formation of advanced glycation end-products: A mechanistic investigation. Food Chem. 2021, 361, 130102. [CrossRef] [PubMed]

48. Siriamornpun, S.; Kaewseejan, N.; Chumroenphat, T.; Inchuen, S. Characterization of polysaccharides from Gynura procumbens with relation to their antioxidant and anti-glycation potentials. Biocatal. Agric. Biotechnol. 2021, 32, 101957. [CrossRef]

49. Zhang, L.; Xu, L.; Tu, Z.-C.; Wang, H.-H.; Luo, J.; Ma, T.-X. Mechanisms of isoquercitrin attenuates ovalbumin glycation: Investigation by spectroscopy, spectrometry and molecular docking. Food Chem. 2020, 309, 125667. [CrossRef]

50. Wu, X.; Zhang, G.; Hu, M.; Pan, J.; Li, A.; Zhang, Y. Molecular characteristics of gallocatechin gallate affecting protein glycation. Food Hydrocoll. 2020, 105, 105782. [CrossRef]

51. Pan, D.; Zhang, D.; Wu, J.; Chen, C.; Xu, Z.; Yang, H.; Zhou, P. Antidiabetic, antihyperlipidemic and antioxidant activities of a novel proteoglycan from Ganoderma lucidum fruiting bodies on $d b / d b$ mice and the possible mechanism. PLoS ONE 2013, 8 , 10-1371. [CrossRef]

52. Xu, B.; Ji, Y.; Yao, K.; Cao, Y.X.; Ferro, A. Inhibition of human endothelial cell nitric oxide synthesis by advanced glycation end-products but not glucose: Relevance to diabetes. Clin. Sci. 2005, 109, 439-446. [CrossRef] [PubMed]

53. Liu, M.; Yin, H.; Liu, G.; Dong, J.; Qian, Z.; Miao, J. Xanthohumol, a prenylated chalcone from beer hops, acts as an $\alpha$-glucosidase inhibitor in vitro. J. Agric. Food Chem. 2014, 62, 5548-5554. [CrossRef] [PubMed]

54. Wang, S.-H.; Chang, J.-C.; Pokkaew, R.; Lee, J.-F.; Chiou, R.Y.Y. Modified fast procedure for the detection and screening of antiglycative phytochemicals. J. Agric. Food Chem. 2011, 59, 6906-6912. [CrossRef] [PubMed]

55. Sadowska-Bartosz, I.; Galiniak, S.; Bartosz, G. Kinetics of glycoxidation of bovine serum albumin by glucose, fructose and ribose and its prevention by food components. Molecules 2014, 19, 18828-18849. [CrossRef]

56. Bouma, B.; Kroon-Batenburg, L.M.J.; Wu, Y.-P.; Brünjes, B.; Posthuma, G.; Kranenburg, O.; de Groot, P.G.; Voest, E.E.; Gebbink, M.F.B.G. Glycation induces formation of amyloid cross- $\beta$ structure in albumin. J. Biol. Chem. 2003, 278, 41810-41819. [CrossRef] [PubMed]

57. Eze, F.N.; Leelawatwattana, L.; Prapunpoj, P. Structural stabilization of human transthyretin by Centella asiatica (L.) urban extract: Implications for TTR amyloidosis. Biomolecules 2019, 9, 10-3390. [CrossRef] 
58. Franco, R.R.; Ribeiro Zabisky, L.F.; de Lima Júnior, J.P.; Mota Alves, V.H.; Justino, A.B.; Saraiva, A.L.; Goulart, L.R.; Espindola, F.S. Antidiabetic effects of Syzygium cumini leaves: A non-hemolytic plant with potential against process of oxidation, glycation, inflammation and digestive enzymes catalysis. J. Ethnopharmacol. 2020, 261, 113132. [CrossRef]

59. Li, T.; Wang, L.; Chen, Z.; Zhang, X.; Zhu, Z. Functional properties and structural changes of rice proteins with anthocyanins complexation. Food Chem. 2020, 331, 127336. [CrossRef]

60. Wang, Z.; Zhang, J.; Chen, L.; Li, J.; Zhang, H.; Guo, X. Glycine suppresses AGE/RAGE signaling pathway and subsequent oxidative stress by restoring Glo1 function in the aorta of diabetic rats and in HUVECs. Oxid. Med. Cell. Longev. 2019, 2019, 4628962. [CrossRef]

61. Wang, Z.; Zhang, J.; Wang, L.; Li, W.; Chen, L.; Li, J.; Zhao, D.; Zhang, H.; Guo, X. Glycine mitigates renal oxidative stress by suppressing Nox4 expression in rats with streptozotocin-induced diabetes. J. Pharmacol. Sci. 2018, 137, 387-394. [CrossRef] 